\title{
Large-eddy Simulation of Turbulent Dispersion Effects in Direct Injection Diesel and Gasoline Sprays
}

\author{
Hongjiang Li and Christopher Rutland University of Wisconsin-Madison \\ Hong Im and Francisco Hernandez Perez King Abdullah University of Science and Technology
}

\begin{abstract}
In most large-eddy simulation (LES) applications to two-phase engine flows, the liquid-air interactions need to be accounted for as source terms in the respective governing equations. Accurate calculation of these source terms requires the relative velocity "seen" by liquid droplets as they move across the flow, which generally needs to be estimated using a turbulent dispersion model. Turbulent dispersion modeling in LES is very scarce in the literature. In most studies on engine spray flows, sub-grid scale (SGS) models for the turbulent dispersion still follow the same stochastic approach originally proposed for Reynolds-averaged Navier-Stokes (RANS). In this study, an SGS dispersion model is formulated in which the instantaneous gas velocity is decomposed into a deterministic part and a stochastic part. The deterministic part is reconstructed using the approximate deconvolution method (ADM), in which the large-scale flow can be readily calculated. The stochastic part, which represents the impact of the SGS flow field, is assumed to be locally homogeneous and isotropic and, therefore, governed by a Langevintype equation. The model is applied to the spray $\mathrm{G}$ and spray $\mathrm{H}$ conditions defined by the engine combustion network (ECN) group. Simulation results are compared with the available experimental data for spray characteristics such as penetration rates, mixture fraction profile, and droplet velocity and Sauter mean diameter (SMD) distributions. Simulations with no dispersion and the commonly used RANS-type stochastic model are also performed for comparison purposes. Results show that the turbulent dispersion has a considerable impact on quantitative spray characteristics such as projected liquid volume (PLV) fraction, droplet SMD and velocity, and fuel vapor mixture fractions. On the other hand, the macroscopic spray characteristics such as liquid- and vapor-phase penetrations are not significantly affected by the dispersion modeling. The proposed SGS model also improves the prediction of spray and ignition characteristics at the spray conditions studied in this work.
\end{abstract}

\section{Introduction}

The increasing need for fuel economy and emissions control has promoted great interest in both experimental and numerical studies of fuel sprays in the research and development of modern internal combustion (IC) engines. Describing the spray development in turbulent engine flows requires a detailed understanding of various processes such as the droplet drag and deformation, spray atomization and breakup, and evaporation. At the heart of these models is the instantaneous carrier fluid velocity "seen" by liquid parcels. The fluid velocity variation directly influences the particle dispersion by determining the relative velocity magnitude between the carrier phase and liquid parcels. In applications of computational

Page 1 of 15 fluid dynamics (CFD) to engines, the most popular approach to consider this effect is to divide the instantaneous gas velocity at the droplet location into two parts

$$
u_{g, i}=\widetilde{u_{\imath}}+u_{i}
$$

where $\widetilde{u_{\imath}}$ is the time-averaged velocity in RANS or filtered velocity in LES, and $u_{i}$ " represents the fluctuating velocity in RANS or SGS velocity in LES. In both RANS and LES, $\widetilde{u_{\imath}}$ can be readily sampled at the droplet location, whereas $u_{i}$ " cannot be directly evaluated from the resolved fields, and therefore requires a droplet dispersion model. In a number of studies, the conceptual difference in the interpretation of the instantaneous velocity and the reasoning to build the droplet dispersion models are absent. Currently the most common approach to estimate $u_{i}$ " is the stochastic approach developed by Gosman and Loannides [1], in which turbulence is assumed to be isotropic and to possess a Gaussian probability distribution, and $u_{i}$ " is then sampled from a Gaussian distribution with zero mean and a variance related to the SGS turbulent kinetic energy.

Despite the conceptual differences between LES and RANS, in LES spray computations the RANS-type stochastic approach is commonly used. The main drawback of using this approach concerns the fact that it builds on statistical averages, whereas the LES flow field is deterministic and instantaneous. A typical time history of $u_{i}$ " for the RANS-type model is illustrated in Figure 1a, showing that a sampled $u_{i}$ " remains fixed until the droplet is assumed to pass a turbulent eddy. The next sample is unconnected with the previous one, therefore the $u_{i}$ " history is discontinuous in time. This model is also termed as the "discrete random walk (DRW)" model.

Some work on LES has focused on the SGS dispersion modeling. One approach consists in applying ADM on the resolved fluid field, resulting in a deterministic, instantaneous velocity field that can be used to evolve the spray droplets [2,3]. It has been shown that results obtained through ADM are in good agreement with those obtained by direct numerical simulation (DNS) in some cases. However, in practice, ADM can only retrieve the SGS scales of the order of the LES cut-off width, whereas the effects of smaller scales are neglected. Recently, Pozorski and Apte [4] argued that the SGS flow field can be assumed to be locally isotropic and proposed a stochastic differential equation (SDE) to reconstruct the SGS fluid velocity along particle trajectories. Figure $1 \mathrm{~b}$ shows a typical history of $u_{i}$ " determined from this model. As can be seen, the "steps" are eliminated and, to some extent, the model is more suited for LES. The SDE model by Pozorski and Apte is able to simulate the randomizing effect of SGS dispersion for large-inertia particles. However, for small-inertia particles that tend to follow the flow scales filtered out by LES, the model fails to predict the preferential concentration since it is diffusive in nature. 


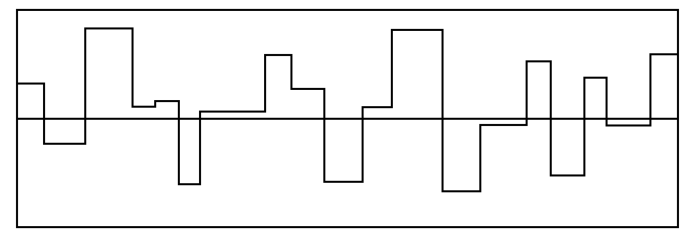

(a) RANS-type DRW model

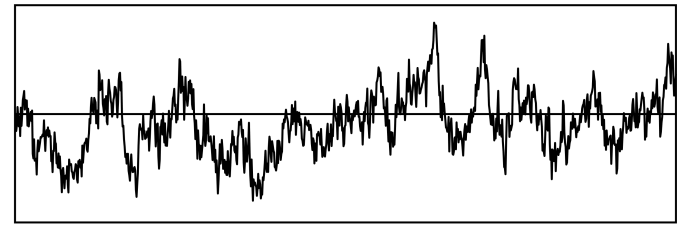

(b) LES-type SDE model

Figure 1. Typical time history of the fluctuating velocity, $u_{i}{ }^{\prime \prime}$, for (a) discrete random walk (DRW) model in RANS, and (b) stochastic differential equation model in LES.

In an attempt to improve the SGS dispersion modeling, in this work, the approximate deconvolution is implemented and employed with a modified Langevin model for the simulations of high-speed evaporating, non-reacting and/or reacting sprays. In the following, the LES governing equations are briefly reviewed, followed by the description of the turbulent dispersion models. Evaluation of the model is then presented for both direct injection gasoline and diesel sprays along with the discussion of the results.

\section{LES Two-Phase Flow Equations and Model Description}

Since the pioneering work of Amsden and O'Rourke [5], the Lagrangian-Eulerian (LE) approach has been a well-established method for spray simulations in internal combustion engine applications. In the LE approach, dispersed liquid droplets are represented as stochastic point processes in a continuous Eulerian frame and the liquid-gas interactions are accounted for as source terms in the gas-phase governing equations. Although the LE method was originally developed for unsteady RANS simulations, it can be easily extended to LES. In this section, LES governing equations based on the LE formulation are briefly described.

\section{Gas Phase Governing Equations}

LES governing equations are obtained by filtering the Navier-Stokes equations and the energy equations. A full derivation of the basic LES equations for compressible flows can be found in Ref. [6]. For the sake of brevity, only the final form of the momentum equation is given

$$
\frac{\partial \bar{\rho}\left\langle u_{i}\right\rangle}{\partial t}+\frac{\partial \bar{\rho}\left\langle u_{i}\right\rangle\left\langle u_{j}\right\rangle}{\partial x_{j}}=\frac{-\partial \bar{P}}{\partial x_{i}}+\frac{\partial \tau_{i j}}{\partial x_{j}}-\frac{\partial \bar{\rho} \Gamma_{i j}}{\partial x_{j}}+S_{i}
$$

where $\rho, P, \tau_{i j}, \Gamma_{i j}, S_{i}$ are the gas-phase density, pressure, molecular stress tensor, SGS stress tensor, and spray source term. The "overbar" and "brackets" represent the spatial filtering and density weighted (Favre) filtering, respectively. In practical applications, filtering is not performed explicitly and is given implicitly by the local cell size.

The term $\Gamma_{i j}$ represents the sub-grid stresses in LES and it cannot be directly computed. To close Equation 2, a model must be used for $\Gamma_{i j}$. In practical applications such as engine flows, the choice of model for Page 2 of 15
$\Gamma_{i j}$ is of great importance. Thorough reviews of LES applications for IC engines have been provided by Rutland [7] and Celik et al [8]. In this study, a mixed one-equation model developed by Tsang et al. [9] based on the work of Pomraning and Rutland [10] is used

$$
\Gamma_{i j}=\frac{2 L_{i j}}{L_{m m}} k_{s g s}-2 v_{n o z}\left(\left\langle S_{i j}\right\rangle-\frac{1}{3} \delta_{i j}\left\langle S_{k k}\right\rangle\right)
$$

where $L_{i j}$ is the Lenard stress tensor, $L_{i j}=\left\langle\widehat{\left.u_{1}\right\rangle\left\langle u_{j}\right.}\right\rangle-\left\langle\widehat{u_{1}}\right\rangle\left\langle\widehat{u_{j}}\right\rangle, v_{n o z}$ is an artificial viscosity in the near-nozzle area, and $S_{i j}$ is the strain rate tensor. The operator denotes a test level filter larger than the cell size.

A revised SGS kinetic energy transport equation was proposed by Bharadwaj and Rutland [11] by including a spray source/sink term to account for the spray induced effects on the SGS level, which is employed here. The equation is written as

$$
\begin{aligned}
\frac{\partial \bar{\rho} k_{s g s}}{\partial t}+\frac{\partial \bar{\rho} k_{s g s}\left\langle u_{j}\right\rangle}{\partial x_{j}} & \\
= & -\frac{\partial}{\partial x_{j}}\left(\mu_{T} \frac{\partial k_{s g s}}{\partial x_{j}}\right)-\bar{\rho} \Gamma_{i j} \frac{\partial\left\langle u_{i}\right\rangle}{\partial x_{j}} \\
& -\varepsilon_{s g s}+W_{s, s g s}
\end{aligned}
$$

where $\mathrm{k}_{\mathrm{sgs}}, \mu_{\mathrm{T}}, \Delta, \varepsilon_{\mathrm{sgs}}, \dot{\mathrm{W}}_{\mathrm{s}, \mathrm{sgs}}$ are the SGS turbulent kinetic energy, SGS turbulence viscosity, LES filter width, SGS energy dissipation rate, and spray source terms, respectively. The form of the modeled SGS energy dissipation rate, $\varepsilon_{\text {sgs }}$, is written as [12]

$$
\varepsilon_{s g s}=C_{\varepsilon} \bar{\rho} \frac{k_{s g s}^{3 / 2}}{\Delta}
$$

where $C_{\varepsilon}$ is a constant with a nominal value of 0.3 . Since the SGS kinetic energy is positive everywhere, Equation 5 conveniently guarantees that $\varepsilon_{\mathrm{sgs}}$ acts as a sink for the SGS kinetic energy, $\mathrm{k}_{\mathrm{sgs}}$.

The spray source terms in Equations 2 and 4 are expressed as

$$
\begin{gathered}
S_{i}=-\sum_{N=1}^{N d}\left(F_{d, i}+\dot{m}_{d} v_{d, i}\right) / V_{c e l l} \\
W_{s, s g s}=-\sum_{N=1}^{N d} F_{d, i}\left(2\left\langle u_{i}\right\rangle-3\left\langle\left\langle u_{i}\right\rangle\right\rangle+\left\langle\left\langle\left\langle u_{i}\right\rangle\right\rangle\right\rangle\right) \\
/ V_{\text {cell }}
\end{gathered}
$$

where the contributions from liquid droplets are summed over all parcels located within each computational cell. The terms $m_{d}, V_{\text {cell }}$, and $\mathrm{Nd}$ represent the rate of change of droplet mass (i.e., the mass vaporization rate), cell volume, and the number of droplets within the computational cell. $F_{d, i}$ is the aerodynamic drag force and its formulation will be given below.

\section{Lagrangian Droplet Equations}

The dispersed liquid phase is described by solving the droplet distribution function (DDF), which consists of independent variables such as Lagrangian position, velocity vector, and diameter. Additional variables can be added to the DDF without violating the generality. A valid statistical description of the spray development requires a tremendous amount of spray droplets. To reduce the computational cost, liquid "parcels" are used in most CFD codes, with each parcel consisting of several droplets having the same physical properties. Sub-models for the spray breakup, evaporation, 
and collision processes are then applied to each individual parcel. The Lagrangian equations for liquid parcels are

$$
\begin{aligned}
& \frac{d x_{d, i}}{d t}=v_{d, i} \\
& \frac{d v_{d, i}}{d t}=\frac{F_{d, i}}{m_{d}}
\end{aligned}
$$

where $x_{d, i}, v_{d, i}, m_{d}$ are droplet position, velocity, and mass, respectively.

The aerodynamic drag force is modeled using a linear drag law [5]

$$
F_{d, i}=\frac{3}{4} \frac{\bar{\rho}}{\rho_{l}} \frac{m_{d}}{d_{d}} C_{d}\left(u_{g, i}-v_{d, i}\right)\left|u_{g, i}-v_{d, i}\right|
$$

where $\rho_{l}, d_{d}, C_{D}$ are the droplet density, diameter, and drag coefficient, respectively. The drag coefficient is calculated as follows

$$
C_{D}=\left\{\begin{aligned}
\frac{24}{R e_{d}}\left[1+\frac{1}{6}\left(R e_{d}\right)^{2 / 3}\right], & R e_{d} \leq 1000 \\
0.424, & R e_{d}>1000
\end{aligned}\right.
$$

where the Reynolds number is defined as $\operatorname{Re}_{\mathrm{d}}=\bar{\rho}\left|u_{g, i}-v_{d, i}\right| d_{d} /$ $\mu_{g}$ and $\mu_{g}$ is the dynamic viscosity of the ambient gas.

\section{Turbulent Dispersion Model}

Equations 2-9 partially describe the interactions between the gasphase and liquid droplets. The remaining problem is to determine the instantaneous gas velocity at the droplet location, $u_{g, i}$. Currently, the most popular approach to estimate $u_{g, i}$ consists in splitting it into a time or spatial averaged part and a fluctuating part, as in Equation 1. In the remaining of this section, the commonly used DRW model and current SGS model will be described.

\section{DRW model}

In the DRW model, $\widetilde{\mathrm{u}}_{1}$ in Equation 1 is assumed to be the resolved gas-phase velocity, $\left\langle u_{i}\right\rangle$. The fluctuating part, $u_{i}{ }^{\prime \prime}$, is selected from a Gaussian distribution with a standard deviation that is equal to the characteristic SGS velocity, $u_{k, s g s}=\sqrt{2 k_{s g s} / 3}$. The Gaussiandistribution has a mean of zero and is given by

$$
G\left(u_{i}^{\prime \prime}\right)=\frac{1}{\sqrt{2 \pi u_{k, s g s}^{2}}} \exp \left(-\frac{u_{i}{ }^{2}}{2 u_{k, s g s}^{2}}\right)
$$

The fluctuating velocity, $u_{i}{ }^{\prime \prime}$, is kept as constant until the droplet is assumed to pass a turbulent eddy. This droplet-eddy interaction is determined by two characteristic timescales, one corresponds to the time required for the droplet to pass through a turbulent eddy, $\tau_{p}$, and the other to the eddy lifetime, $\tau_{e}$. Various approaches have been reported in the literature to estimate $\tau_{p}$, as reviewed by MacInnes and Bracco [13]. One of the most commonly used methods, proposed by Gosman and Ioannides [1], assumes it to be

$$
\tau_{p}=0.1643 \frac{\bar{\rho} k_{s g s}^{1.5}}{\varepsilon_{s g s}\left|u_{C}\right|}
$$

where $\mathrm{u}_{\mathrm{C}}$ is a characteristic velocity which can be estimated using various formulas. In this work, it is set to be the relative velocity between the droplet and ambient gas, i.e., $\mathrm{u}_{\mathrm{C}}=\left(\mathrm{u}_{\mathrm{g}, \mathrm{i}}-\mathrm{v}_{\mathrm{d}, \mathrm{i}}\right)$. The eddy lifetime, $\tau_{e}$, is estimated to be

$$
\tau_{e}=\frac{\bar{\rho} k_{s g s}}{\varepsilon_{s g s}}
$$

Once $u_{i}$ "is selected from the Equation 10, its lifetime is recorded and compared to the droplet eddy interaction time, $\tau_{i}$, which can be written as

$$
\tau_{i}=\min \left(\tau_{p}, \tau_{e}\right)
$$

If the lifetime of $u_{i}$ " is greater or equal to $\tau_{i}$, a new $u_{i}$ " will be selected from Equation 10.

\section{SGS model}

In the current SGS model, $u_{g, i}$ is assumed to contain two parts

$$
u_{g, i}=u_{i}^{*}+u_{i}
$$

where $u_{i}^{*}$ is the approximate deconvoluted velocity and $u_{i} "$ is the SGS part. Assuming that the LES filter kernel $G$ has an inverse $G^{-1}$, which can be approximated by the truncated Van Cittert series expansion [14], $u_{i}^{*}$ can then be obtained by consecutively applying the filter

$$
\begin{aligned}
& u_{i}^{*}=\sum_{\alpha=0}^{N}(I-G)^{\alpha} *\left\langle u_{i}\right\rangle \\
& =\left\langle u_{i}\right\rangle+\left(\left\langle u_{i}\right\rangle-\left\langle\left\langle u_{i}\right\rangle\right\rangle\right)+\left(\left\langle u_{i}\right\rangle-2\left\langle\left\langle u_{i}\right\rangle\right\rangle+\left\langle\left\langle\left\langle u_{i}\right\rangle\right\rangle\right\rangle\right) \\
& +\ldots
\end{aligned}
$$

The first term on the right-hand side of Equation 15 is the filtered gas velocity obtained from Equation 2 . The other terms represent the unresolved flow structures computed by filtering $u_{i}$ with a test filter. The test filtering is defined in the real space and thus can be computed from the available LES field. It was found that the first three terms in Equation 15 can give reasonable results [6], and that including more terms may not improve the results significantly. Therefore, in this work, we set $\mathrm{N}=2$, which results in the following expression for $\mathrm{u}_{\mathrm{i}}^{*}$

$$
u_{i}^{*}=3\left\langle u_{i}\right\rangle-3\left\langle\left\langle u_{i}\right\rangle\right\rangle+\left\langle\left\langle\left\langle u_{i}\right\rangle\right\rangle\right\rangle
$$

Note that the ADM can only recover flow scales on the order of or larger than the LES filter size. The SGS fluid velocity, $u_{i}$ ", cannot be explicitly resolved and must be modeled. In the context of LES, liquid droplets subjected to the instantaneous SGS flow structures can be related to the Brownian motion (i.e., the apparently random movement of a particle in a fluid due to collisions with the molecules of the fluid) and, consequently, be governed by a Langevin-type equation. In the present study, the SDE proposed by Pozorski and Apte [4] is employed

$$
d u_{i}^{\prime \prime}=-\frac{u_{i}^{\prime \prime}}{\tau_{L}} d t+\sqrt{\frac{2 u_{k, s g s}^{2}}{\tau_{L}}} d W_{i}
$$

where $\tau_{L}$ is a characteristic time scale and $d W_{i}$ is an increment of the Wiener process.

Crowe et al. [15] have observed that small and large droplets behave differently when subjected to a turbulent flow. They proposed the 
following scaling factor (Stokes number) to assess the impact of large eddies on droplet dispersion

$$
S t=\frac{\tau_{m}}{\tau_{F}}=\frac{\rho_{l} d_{d}^{2}\left|u_{g, i}-v_{d, i}\right|}{18 \mu \Delta}
$$

where $\tau_{\mathrm{m}}=\rho_{l} d_{d}^{2} / 18 \mu$ is the aerodynamic response time and $\tau_{\mathrm{F}}=$ $\Delta /\left|\mathrm{u}_{\mathrm{g}, \mathrm{i}}-\mathrm{v}_{\mathrm{d}, \mathrm{i}}\right|$ is the characteristic time scale associated with large eddies. Small droplets with $\mathrm{St}<1.0$ tend to follow the gas flow. For St $>>1.0$, large eddies have insufficient time to influence the droplets motion. To take the impact of St into consideration, we proposed the following form of $\tau_{L}$ based on the work of Pozorski and Apte [4]

$$
\tau_{L}=\left\{\begin{aligned}
c_{s g s} \Delta / u_{k, s g s}, & S t \leq 1 \\
c_{s g s} \Delta / u_{k, s g s} \sqrt{1+\epsilon^{2}}, & S t>1
\end{aligned}\right.
$$

where $\epsilon$ is the normalized drift velocity, $\epsilon=\left|\left\langle\mathrm{u}_{\mathrm{i}}\right\rangle-v_{d, i}\right| / u_{k, s g s}$, and $c_{s g s}$ is a constant with a nominal value of one.

\section{Experiment and Simulation Setup}

Two sets of experimental data were taken from the ECN database and used for the evaluation of dispersion models. Spray experiments were conducted in constant volume combustion vessels under predefined engine-like conditions, which were simulated by igniting a premixed combustible gas mixture that burns to completion. One of them, termed as "spray G", corresponds to a non-reacting early injection case in DISI engines [16]. The reaming one, termed as "spray H", represents combustion conditions relevant to diesel engines. The injection conditions and injector parameters of both spray experiments are given in Table 1 .

The OpenFOAM CFD framework was used for implementing the models and running LES spray simulations. The atomization and breakup of spray $\mathrm{H}$ and spray $\mathrm{G}$ were simulated using the KH-RT model [17] and the integrated atomization/breakup model (to be published), respectively. Features of the IAB model are given in Appendix A. The mesh used for spray $\mathrm{H}$ simulations has a dimension of $80 \times 80 \times 100 \mathrm{~mm}$ with static mesh refinement to cover the liquid and vapor regions. The minimum cell size is about $0.5 \mathrm{~mm}$. Spray G simulations were run using a cubical domain with a length of 100 $\mathrm{mm}$. The mesh was modified to include a cutout approximating the shape and location of the DISI multi-hole injector. This cutout, though not very detailed, was found to be necessary to correctly capture near-nozzle entrainment flow [18]. The initial ambient velocities were set to zero for spray simulations. The initial $\mathrm{k}_{\mathrm{sgs}}$ was set to be $0.0079 \mathrm{~m}^{2} / \mathrm{s}^{2}$ for spray G conditions, based on the ECN recommendations [16]. For diesel spray $\mathrm{H}$ conditions, the ambient gas in the vessel has higher values of density and temperature, and therefore the initial $\mathrm{k}_{\mathrm{sgs}}$ is also higher. In this work, the initial $\mathrm{k}_{\mathrm{sgs}}$ for spray $\mathrm{H}$ was set to be $0.6 \mathrm{~m}^{2} / \mathrm{s}^{2}$. In our experience, the initial value of $\mathrm{k}_{\mathrm{sgs}}$ has little impact on the results as long as its value is non-zero. The initial gas-phase pressure, temperature, and liquid-phase temperature were set according to the experimental conditions listed in Table 1. More details about the mesh and initialization can be found in Ref. [19].

Table 1. Conditions and injector specifications for ECN evaporating spray $\mathrm{H}$ and spray G.

\begin{tabular}{|r|r|r|}
\hline Data type & Spray H & Spray G \\
\hline Fuel & n-heptane & iso-octane \\
\hline \hline Ambient gas density $\left(\mathrm{kg} / \mathrm{m}^{3}\right)$ & 14.8 & 3.5 \\
\hline
\end{tabular}

Page 4 of 15

\begin{tabular}{|r|r|r|}
\hline Ambient gas composition (-) & $\mathrm{N}_{2}, \mathrm{CO}_{2}, \mathrm{H}_{2} \mathrm{O}, \mathrm{O}_{2}$ & $\mathrm{~N}_{2}$ \\
\hline Ambient gas temperature $(\mathrm{K})$ & 1000.0 & 573.0 \\
\hline Ambient gas pressure $(\mathrm{MPa})$ & 4.33 & $5.97 \times 10^{-1}$ \\
\hline Ambient gas velocity $(\mathrm{m} / \mathrm{s})$ & $\approx 0$ & $\approx 0$ \\
\hline Fuel temperature $(\mathrm{K})$ & 373 & 363 \\
\hline Injector orifice diameter $(\mathrm{mm})$ & 0.100 & 0.165 \\
\hline Injection pressure $(\mathrm{MPa})$ & 154.33 & 20.0 \\
\hline Injection duration $(\mathrm{ms})$ & 6.8 & 0.78 \\
\hline Injected fuel mass $(\mathrm{mg})$ & 17.8 & 10.0 \\
\hline
\end{tabular}

The rate of injection (ROI) profiles for both diesel and gasoline spray simulations were taken from the measurements and are plotted in Figure 2. Note that the ROI for spray H resembles a "square-wave" profile, resulting in a "quasi-steady" spray structure for the liquid phase. LES simulations for spray $\mathrm{H}$ were therefore performed with a single realization only. Spray G, on the other hand, has insufficient injected quantity to promote a quasi-steady spray structure and therefore results in highly transient sprays. Simulation results of the standard spray $G$ presented in the remaining of this paper are the average of five realizations, each with a different random number seed in the injection model, as suggested by Sphicas et al. [20].

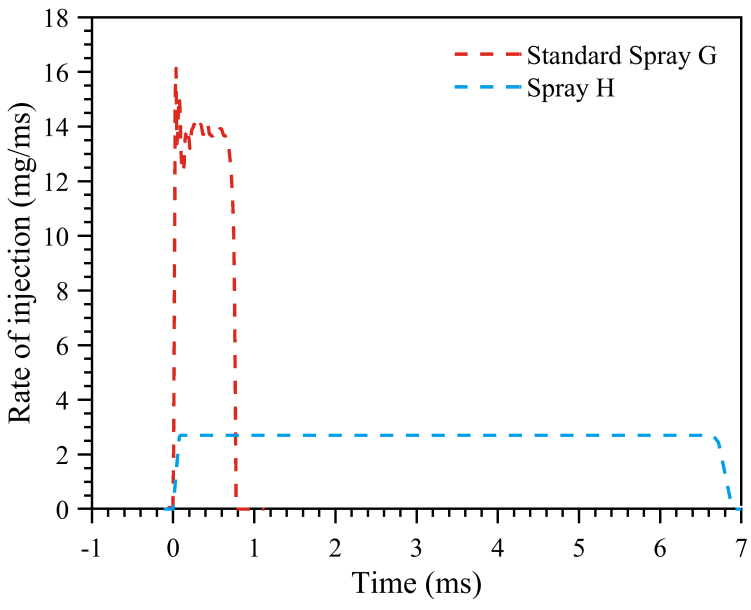

Figure 2. Measured rate of injection profiles at the standard spray $\mathrm{G}$ and spray $\mathrm{H}$ conditions.

Simulations of the spray $\mathrm{G}$ were carried out following the ECN convention displayed in Figure 3. Note that the coordinates origin has been defined as the tip of the nozzle, which means the eight nozzle holes are located at slightly negative axial positions. The plume direction and plume cone angles are two critical parameters affecting plume-to-plume interactions, as one may expect. Unfortunately, these parameters can hardly be measured due to the difficulties and uncertainties associated with experimental measurements in the nearnozzle region. Consequently, in this work, the plume direction was estimated using a variable profile ranging from $37^{\circ}$ to $33^{\circ}$ according to the experimental work of Manin et al. [21]. The plume cone angle was set to $25^{\circ}$ based on a previous study by Pickett [22]. 

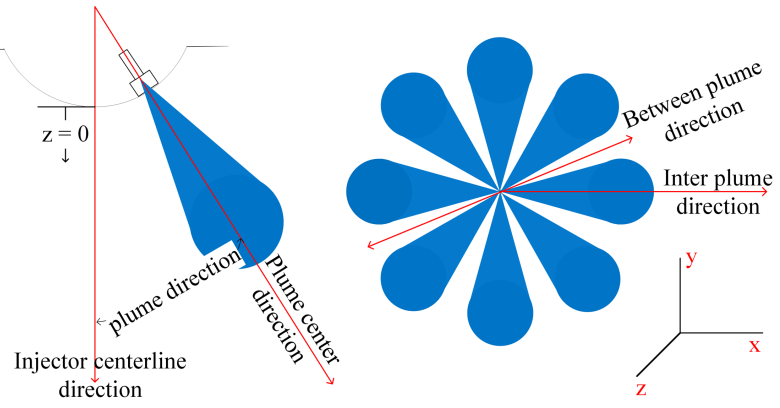

Figure 3. Schematic of the spray $\mathrm{G}$ coordinates for simulation setup and data processing.

\section{Data acquisition and processing}

Experimental data were collected from the ECN website and related publications. Those data include liquid- and vapor-phase penetrations, PLV profiles, temporal evolution of the gas-phase velocity, and spatial distributions of droplet velocities and SMD, and fuel vapor mixture fractions. Table 2 lists the specific data types and their sources for each spray experiments. In each entry, the measurements devices are also specified. Details of the experimental setup are not provided here for the sake of brevity.

Table 2. Summary of experimental data used in this work.

\begin{tabular}{|l|l|l|}
\hline Data type & Spray G & Spray H \\
\hline Liquid penetration & $\begin{array}{l}\text { Mie-Scatter, Manin } \\
\text { et al. [21] }\end{array}$ & $\begin{array}{l}\text { Mie-Scatter, SNL } \\
{[23]}\end{array}$ \\
\hline $\begin{array}{l}\text { Liquid extinction } \\
\text { length }\end{array}$ & $\begin{array}{l}\text { DBI, Manin et al. } \\
{[21]}\end{array}$ & - \\
\hline PLV profiles & $\begin{array}{l}\text { DBI, Joshua Lacey } \\
{[24]}\end{array}$ & - \\
\hline $\begin{array}{l}\text { Droplet velocity } \\
\text { and SMD }\end{array}$ & $\begin{array}{l}\text { PDI, Scott Parrish } \\
{[25]}\end{array}$ & - \\
\hline $\begin{array}{l}\text { Gas-phase velocity } \\
\text { PIV, SNL, [16] }\end{array}$ & - \\
\hline $\begin{array}{l}\text { Vapor penetration } \\
\text { Schlieren, SNL and } \\
\text { Institute Motori [16] }\end{array}$ & Schlieren, SNL [23] \\
\hline $\begin{array}{l}\text { Mixture fraction } \\
\text { distribution }\end{array}$ & - & $\begin{array}{l}\text { Rayleigh scattering, } \\
\text { SNL [23] }\end{array}$ \\
\hline Ignition delay & - & $\begin{array}{l}\text { Chemiluminescence, } \\
\text { SNL [23] }\end{array}$ \\
\hline
\end{tabular}

Simulation results were processed following the ECN standards and recommendations if applicable [26]. Macroscopic spray characteristics such as the liquid- and vapor phase penetrations were calculated using the methods summarized in Table 3 . The predicted vapor-phase penetration is defined as the axial distance along the nozzle centerline where the local fuel mixture fraction is $0.1 \%$. Lineof-sight measurement techniques, such as volume-illuminated Miescattering and diffused backlit imaging (DBI), have been utilized by ECN to visualize macroscopic spray characteristics such as liquid penetration and spray angles. With Mie-scattering, the light signal is proportional to the square of the incident particle diameter [27]. DBI or laser absorption use light extinction (light deflection or absorption) produced by the spray droplets, thus providing a measure related to the cube of droplet diameter [28]. On the other hand, the conventional way to determine liquid penetration in most CFD studies is based on accumulated liquid mass fraction. To reduce the difference between the numerical and experimental methods of measuring liquid penetration, the liquid phase penetration is Page 5 of 15 determined using two methods, namely, the mimic Mie-scatter (MMS) method [29] and the PLV method [24].

Table 3. Post-processing methods for the estimation of liquid- and vaporphase penetrations.

\begin{tabular}{|c|c|}
\hline Data type & Method \\
\hline Vapor penetration & $\begin{array}{l}\text { Maximum axial distance with a minimum } \\
\text { fuel mass fraction of } 0.1 \%\end{array}$ \\
\hline \multirow{3}{*}{ Liquid penetration } & 1. MMS method for Mie-scatter imaging \\
\hline & 2. PLV method for DBI measurements \\
\hline & $\begin{array}{l}\text { 3. Axial distance from the nozzle tip } \\
\text { where the accumulated liquid mass } \\
\text { fraction is } 99 \% \text { (Only for spray } \mathrm{H} \text { ) }\end{array}$ \\
\hline
\end{tabular}

Assuming that the $\mathrm{x}$-axis is the camera line-of-sight direction, the total droplet surface area or volume for each CFD cell is calculated and projected along the $\mathrm{x}$-direction, resulting in a two-dimensional map of integrated droplet surface area or volume. The liquid-gas bound is then defined using a predefined threshold. For the integrated droplet surface area method, this threshold is selected to be roughly equal to $3 \%$ of the maximum integrated surface area [29]. For the projected liquid volume method, the ECN recommended "high" threshold is chosen in this work [28]: $2.0 \times 10^{-3} \mathrm{~mm}^{3}$-liquid $/ \mathrm{mm}^{2}$.

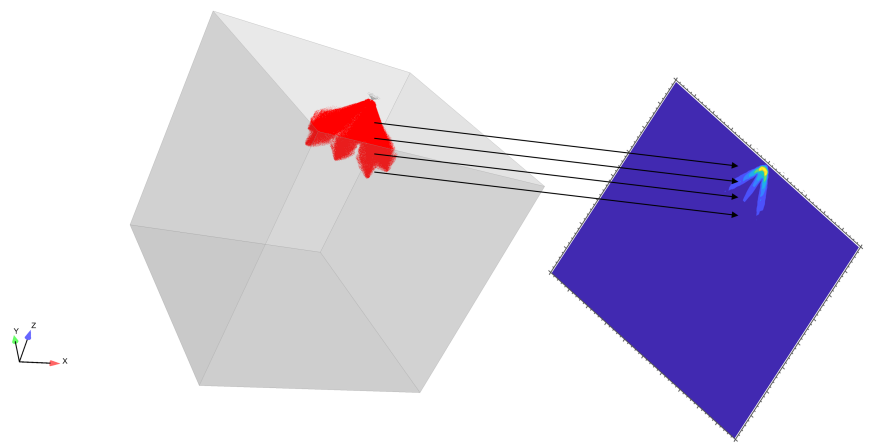

Figure 4. Schematic of the line-of-sight methods for the estimation of liquid penetrations.

\section{Results and Discussions}

Results at the ECN standard spray G conditions will be discussed first. Then, results at the evaporating spray $\mathrm{H}$ conditions at the ambient temperature of $1000 \mathrm{~K}$ will be presented, followed by a brief discussion of the ignition characteristics under reacting spray $\mathrm{H}$ conditions with an oxygen level of $21 \%$-vol.

\section{Standard Spray G Condition}

Figures 5 and 6 show the axial liquid penetration from experimental measurements and simulations. Experimental data are plotted with a shaded area representing the standard deviations, if available. Predicted penetration results are processed using the MMS and PLV methods and ensemble-averaged over five realizations. The first observation concerning the results shown in Figures 5 and 6 is that the SGS dispersion model tends to predict shorter liquid residence time (i.e., the time when liquid penetration falls back to zero). This is primarily due to the enhanced turbulent dispersion effects as will be discussed later. The turbulent dispersion does not affect the liquid penetration during the initial period of injection $(t<0.5 \mathrm{~ms}$ ASOI). As injection proceeds, however, it is noticed that differences among 
simulation results become larger, especially in the downstream of spray where the droplets are significantly influenced by the turbulent ambient gas field. One possible reason is that the liquid droplets in the downstream are having much smaller sizes and velocities compared to those in the near-nozzle region, due to droplet breakup, evaporation, and aerodynamic drag. Hence, the associated Stokes number is very small as well. According to Ref. [15], those droplets should maintain a near velocity-equilibrium with the ambient gas, which eventually gives shorter liquid penetration since the liquidphase is more dispersed. Overall, the present SGS model slightly under-predicts the liquid penetration compared to the other two models but captures the liquid residence time fairly well.

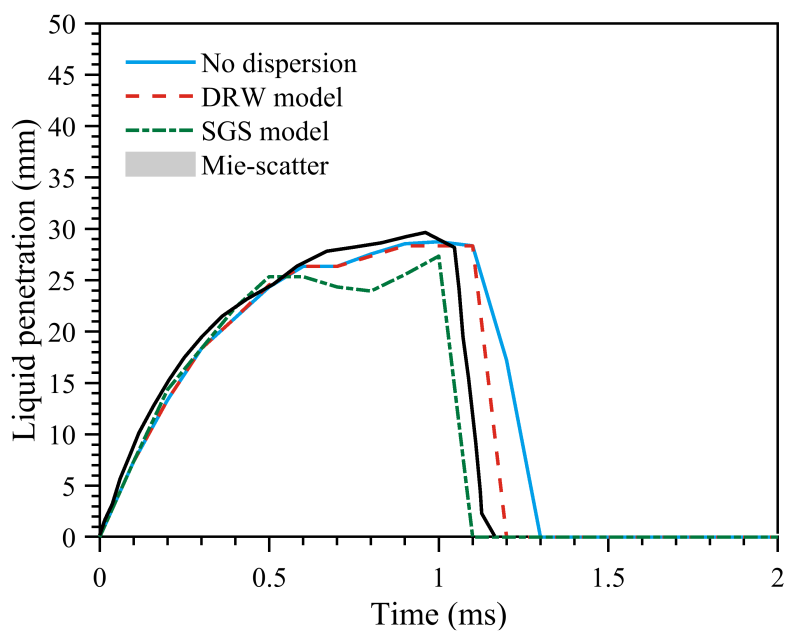

Figure 5. Axial liquid-phase penetration at the standard spray $\mathrm{G}$ condition. The results from Mie-scatter imaging are plotted with the mean only. The LES results are processed using the mimic Mie-scatter method and ensembleaveraged over five realizations.

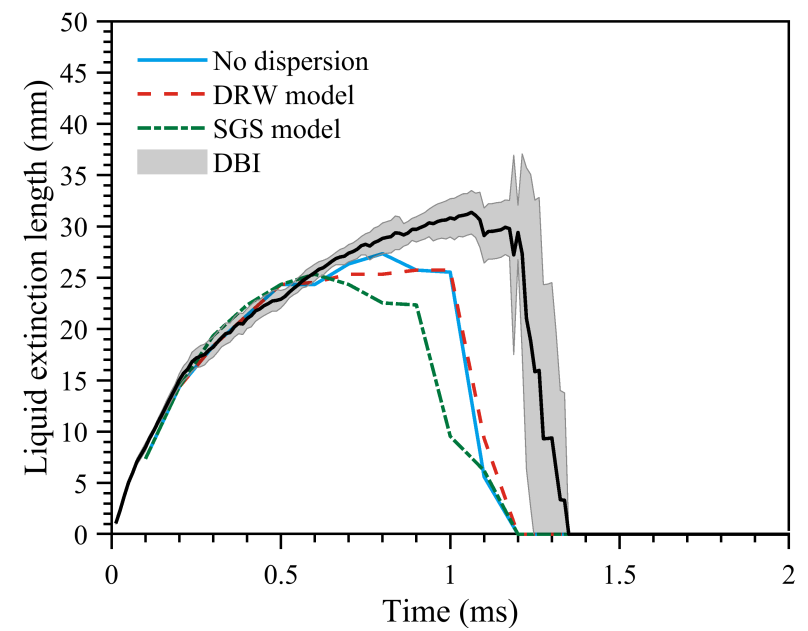

Figure 6. Axial liquid extinction length at the standard spray $\mathrm{G}$ condition. The results from DBI imaging are plotted with the shaded area representing the standard deviation. The LES results are processed using the projected liquid volume method with the threshold of $2.0 \times 10^{-3} \mathrm{~mm}^{3}$-liquid $/ \mathrm{mm}^{2}$ and ensemble-averaged over five realizations.

Moving to the vapor-phase penetration results plotted in Figure 7, the predicted curves are fairly similar, suggesting little sensitivity of the vapor phase to the dispersion model. The simulations also overpredict the vapor penetration by as much as $4 \mathrm{~mm}$ (about $8 \%$ of the maximum vapor penetration) compared to the SNL measurements.
However, the trends look very similar. A good agreement can also be found between simulations and Institute Motori measurements.

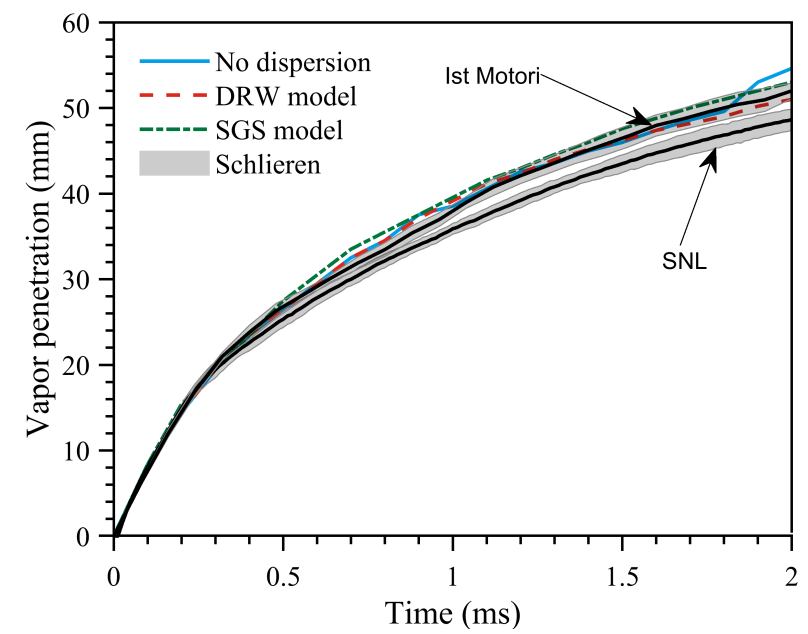

Figure 7. Axial vapor-phase penetration at the standard spray G condition. The results from Schlieren imaging are plotted with error bars representing the standard deviations. The LES results are processed using a threshold of 0.001 mixture fraction and ensemble-averaged over five realizations.

In addition to the liquid penetration rates, the quantitative PLV distributions can be obtained from DBI images. Figure 8 presents the PLV distributions on the nozzle centerline from the DBI measurements [24], along with the ensemble-averaged PLV profiles from simulations. Since the sampling is done along the injector centerline direction (as shown in Figure 3), only five samples are available for processing. Note that experimental data are not available within the first $3 \mathrm{~mm}$ to the injector tip due to the experimental difficulties. In each sub-figure, the spray tip determined from the measured liquid penetration in Figure 6 is illustrated as a vertical dotted line.

Overall, a satisfactory agreement between the DBI measurements and simulations with SGS dispersion is observed. Simulations with no dispersion and DRW dispersion model, on the other hand, overpredict the PLV distributions at the selected times of 0.3, 0.4, 0.6, 0.7 , and $0.8 \mathrm{~ms}$ ASOI. From the injection start to $0.1 \mathrm{~ms}$ (Figure $8 \mathrm{a}$ ), the liquid jet only penetrates about $8.5 \mathrm{~mm}$. Clearly, none of the simulations reproduces the level of PLV within the dense spray region. However, it is questionable whether the PLV in the nearnozzle region should be smaller than that at locations further away from the injector tip. Further downstream, the agreement between simulations and experiments becomes better. Note that the SGS dispersion model already starts to play an important role in the radial dispersion of spray droplets at this early time, as evidenced by the reduced PLV values within the dense spray region.

It is also seen that at later times $(0.3,0.4,0.6$, and $0.7 \mathrm{~ms}$ ASOI) the agreement between experiments and simulations with SGS dispersion becomes better, with the best agreement maintained at distances larger than $8 \mathrm{~mm}$ (see Figures $8 \mathrm{~b}-8 \mathrm{e}$ ). The large differences between simulations and experiments within the dense spray region could be attributed to two factors: uncertainties and difficulties associated with the experiments and insufficient breakup description by the model. The near nozzle analysis from DBI images has always been qualitative due to its long-distance, line-of-sight nature [21]. The second factor is possibly associated with missing or imperfect representation of spray breakup in the near-nozzle region because the in-nozzle turbulence effects are not considered (which can enhance the spray breakup in the near-nozzle region) and insufficient 
experimental data about the plume angle exist. At $0.8 \mathrm{~ms}$ ASOI, the measured axial PLV curve drops rapidly towards zero as shown in
Figure 8f. The predicted PLV distributions also decrease but none of the simulations shows a better correlation with the measured data.

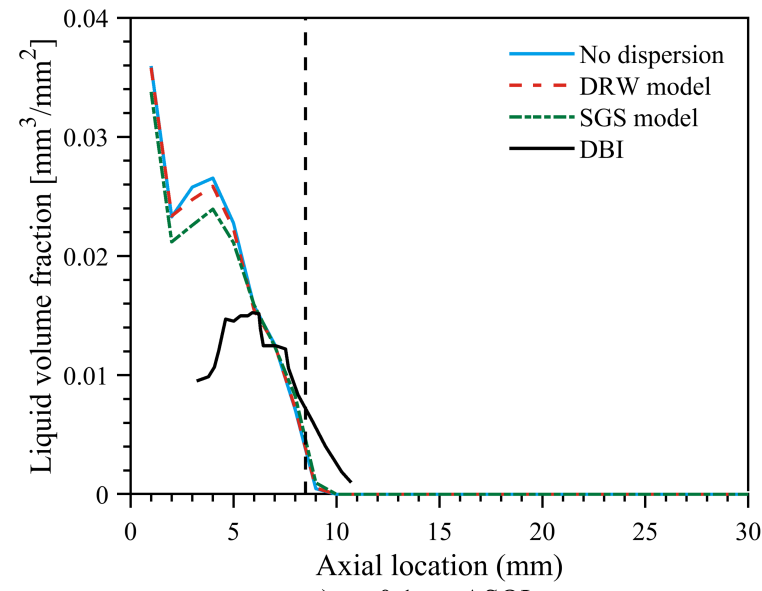

a) $\mathrm{t}=0.1 \mathrm{~ms}$ ASOI

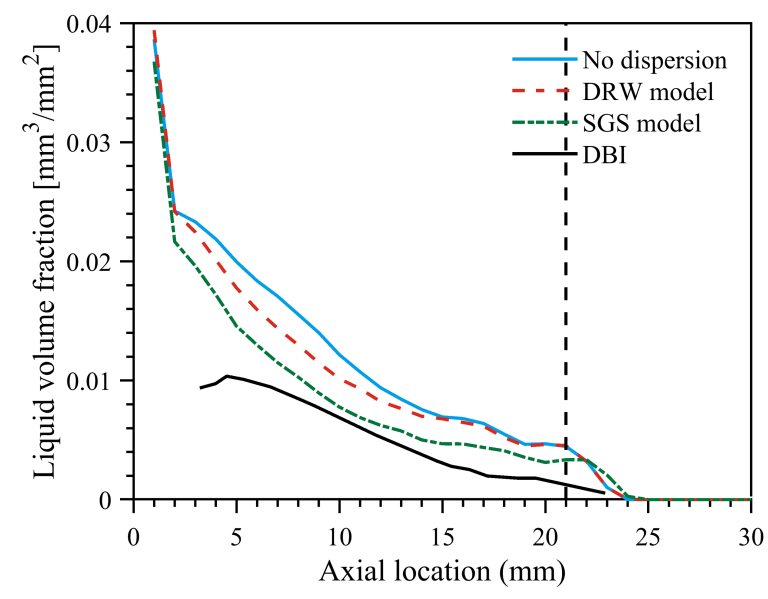

c) $\mathrm{t}=0.4 \mathrm{~ms}$ ASOI

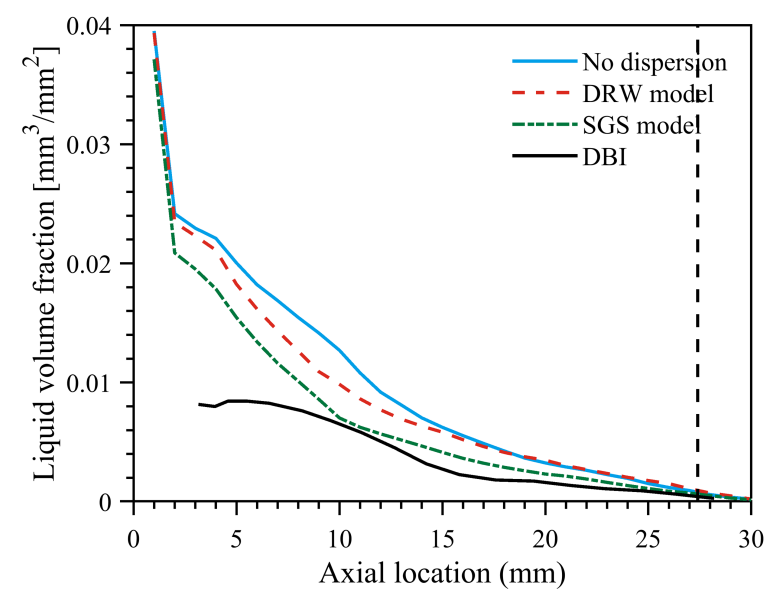

e) $\mathrm{t}=0.7 \mathrm{~ms}$ ASOI

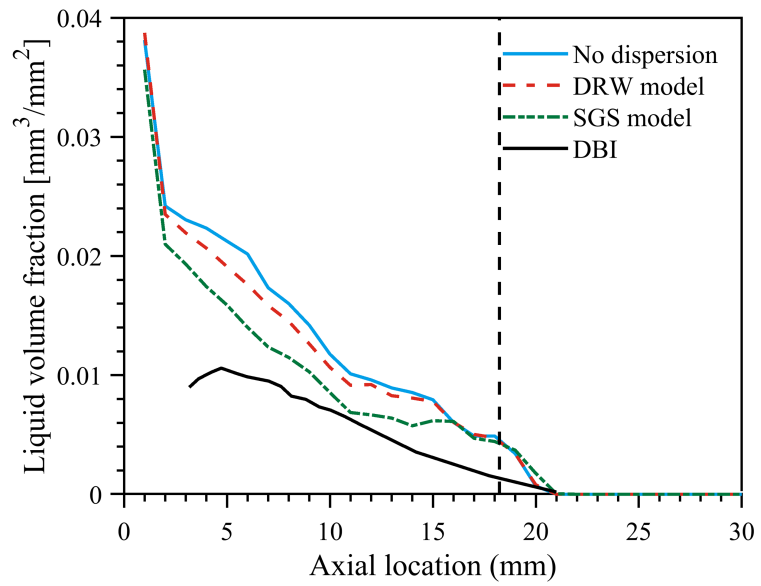

b) $\mathrm{t}=0.3 \mathrm{~ms}$ ASOI
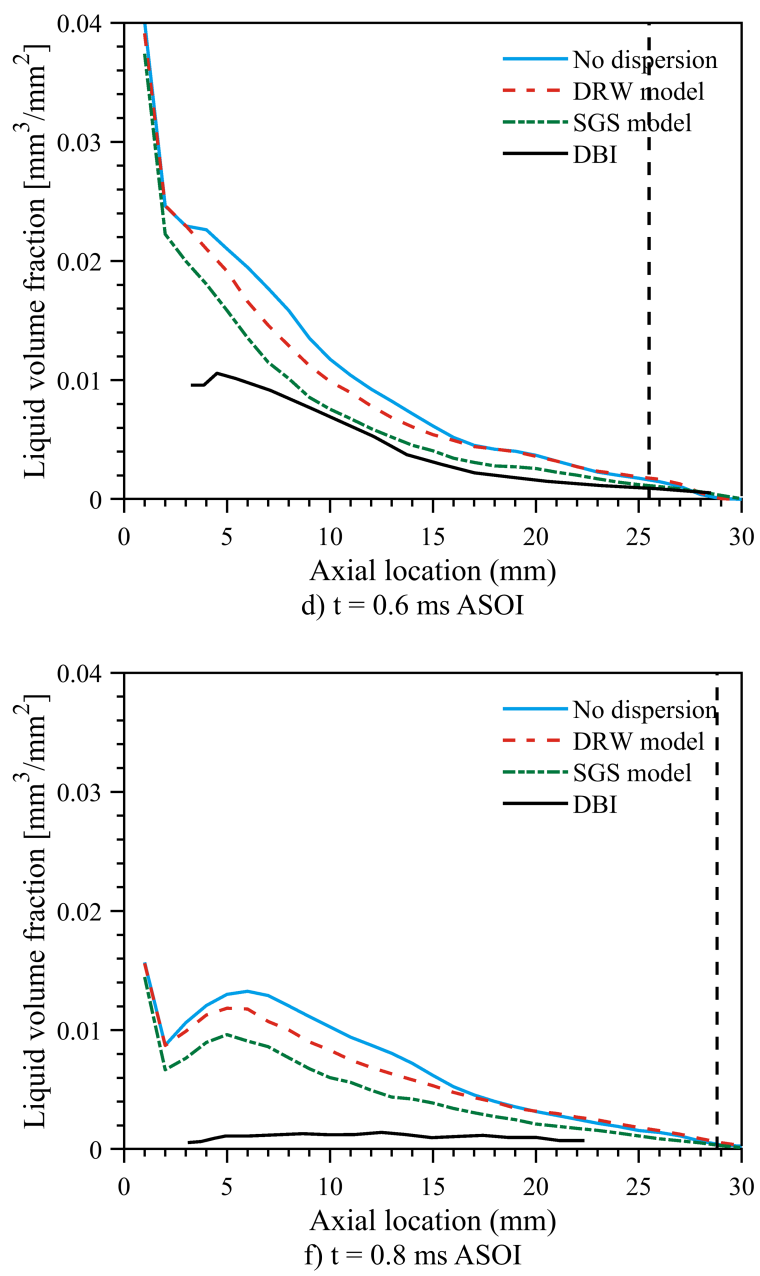

Figure 8. Projected liquid volume fractions on the injector centerline line at various times. Experimental data are plotted using mean values only. LES results are ensemble-averaged over five realizations. In each sub-figure, the liquid penetration is illustrated as a vertical dotted line.

To investigate the reason for the significant impact of the dispersion model on axial PLV distributions, we include the mass-averaged droplet velocity in Figure 9. Both $\mathrm{x}$ - and z-components of the droplet Page 7 of 15 velocity are sampled at $\mathrm{z}=10 \mathrm{~mm}$ axial position at $0.7 \mathrm{~ms}$ ASOI, a timing when the differences among simulations appear to be the largest. Results with no dispersion, DRW model, and SGS model are 
plotted on the left, middle, and right columns, respectively. A comparison of the velocity components in Figure 9 shows higher velocities for the simulations with SGS dispersion model, which indicate that spray droplets are directed in all directions in simulations with SGS dispersion. Considering that the same spray initial/boundary conditions were used, the higher droplet velocity predicted by simulations with SGS dispersion can be related to smaller droplet acceleration. Note that the higher droplet velocities in the $\mathrm{x}$-direction produce more disperse spray plumes. Therefore, the less concentrated PLV on the injector centerline is expected.
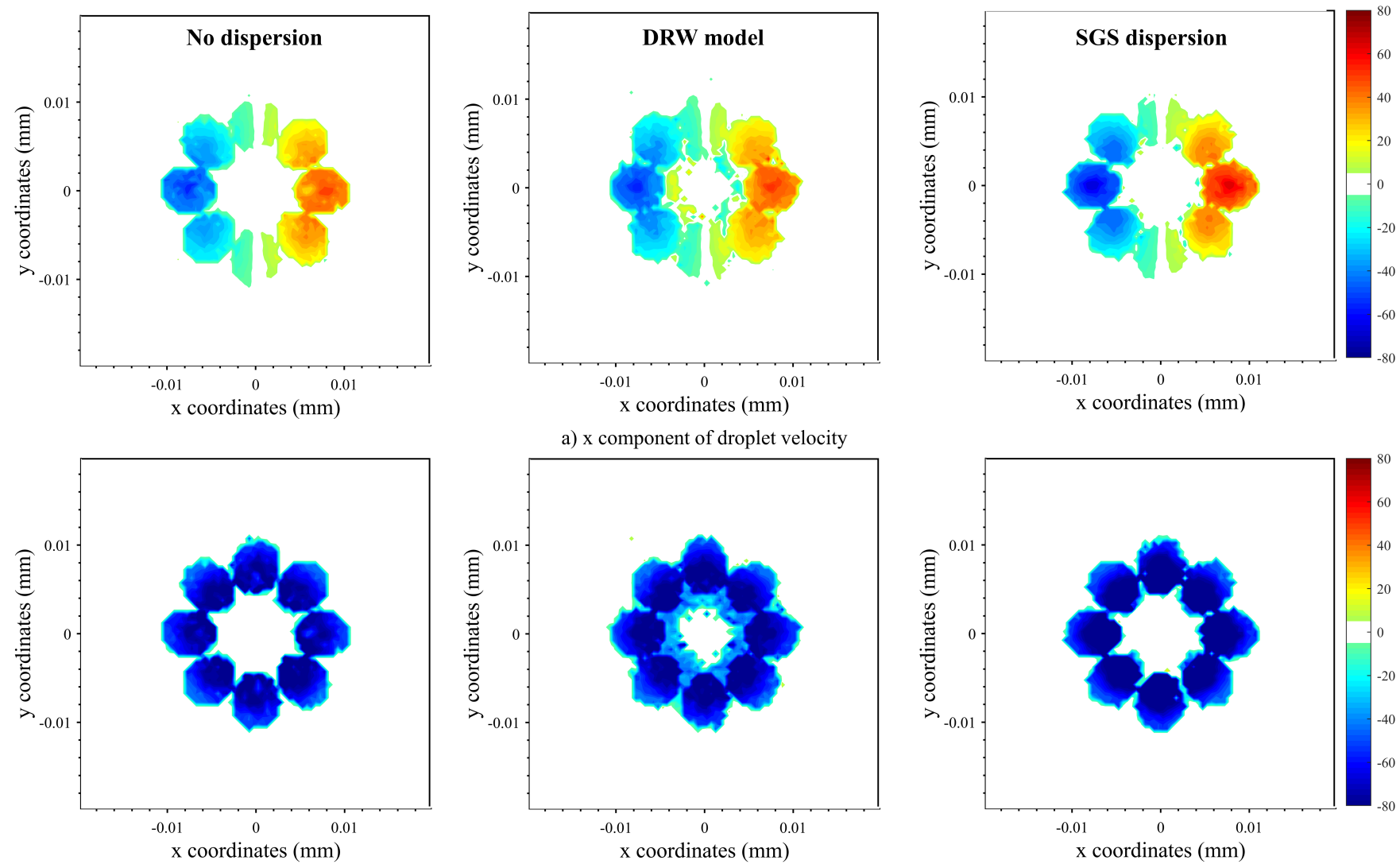

b) z component of droplet velocity

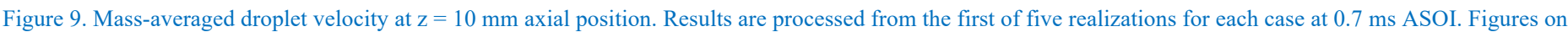

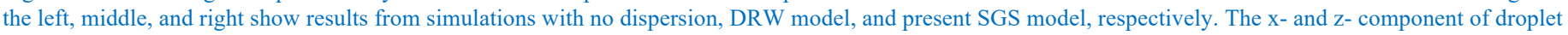
velocity vectors are plotted in the top and bottom rows, respectively.

To further analyze the droplet acceleration, the mass-averaged aerodynamic drag force along the plume center direction (as shown in Figure 3 ) is plotted in Figure 10 at two selected times, 0.7 and $0.9 \mathrm{~ms}$ ASOI, with the results being ensemble-averaged over 40 samples (five realizations, each with eight individual plumes). Intuitively, one can correlate smaller droplet acceleration with smaller aerodynamic drag force. However, this is not necessarily true for the present case. On the contrary, Figure 10 shows that the mass-averaged drag force is the largest in simulations with SGS dispersion, especially at $0.7 \mathrm{~ms}$ ASOI. To explain this, one needs to understand how the acceleration is calculated.

Equation 8 indicates that the aerodynamic drag force is proportional to the droplet surface area. On the other hand, the droplet mass is proportional to the droplet volume. This leads to the following correlation for droplet acceleration

$$
a_{d}=\frac{F_{i, d}}{m_{d}} \propto \frac{d^{2}}{d^{3}}=\frac{1}{d}
$$

where $a_{d}$ is the droplet acceleration. Equation 20 indicates that the droplet acceleration is inversely proportional to the droplet diameter.

Page 8 of 15
Combining the observations from Figures 8 and 9 suggests that the spray breakup may be less violent (i.e., larger droplet sizes) in simulations with SGS dispersion.

Another interesting finding from Figure 10 is that the aerodynamic drag force decreases dramatically within $3 \mathrm{~mm}$ from the nozzle exit during injection, indicating a significant amount of momentum transfer from the liquid phase to the surrounding ambient. The drag force gradually decreases further downstream until it becomes negligible in the far field, implying either a droplet-gas equilibrium (i.e., droplets move with the gas field) or complete vaporization of liquid droplets. At $0.9 \mathrm{~ms}$ ASOI, the injection has already ended, hence no droplet is present in the near-nozzle area. The residual droplets in the downstream region also experience much smaller aerodynamic drag. 


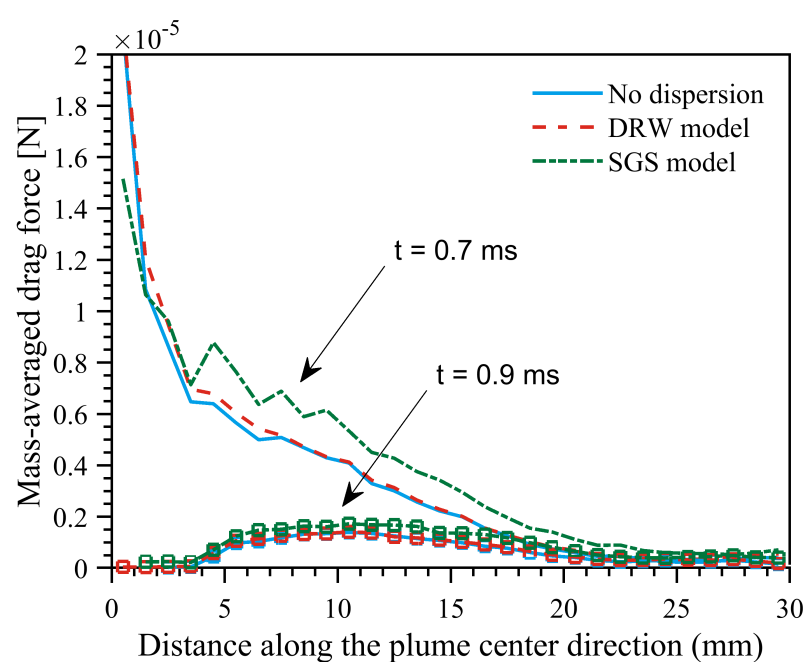

Figure 10. Mass-averaged aerodynamic drag force magnitudes sampled along the plume center direction. Results are ensemble-averaged over five realizations and eight plumes (40 samples in total).

A comparison of the axial droplet velocity and SMD distributions is made in Figure 11. Sampling is done along the inter-plume direction (as shown in Figure 3) at $\mathrm{z}=15 \mathrm{~mm}$ downstream of the injector tip, a location where the experimental data are available. The ensembleaveraged velocity and SMD profiles at selected times of 0.7 and 0.9 $\mathrm{ms}$ ASOI are plotted in the top and bottom sub-figures, respectively.

By focusing on the droplet velocity, an immediate observation is that predictions with SGS dispersion match the experimental curve well. At $0.7 \mathrm{~ms}$ ASOI, a timing representing a quasi-steady state, the measured maximum axial velocity is about $48 \mathrm{~m} / \mathrm{s}$. Predictions with the DRW model and no dispersion model under-estimate this velocity by 6 and $10 \mathrm{~m} / \mathrm{s}$, or roughly $13 \%$ and $20 \%$. At $0.9 \mathrm{~ms}$ ASOI, the injection just ended and therefore the droplet velocities drop gradually. All three simulations predict velocity profiles that match the measured curve well. Although a better match is given by the current SGS dispersion model, the difference is not significant. In addition to the reduced maximum velocity, a shift of the spray plumes towards the injector axis is also observed in simulations and experiments.

Despite showing more fluctuations, the modeling results of droplet SMD match the PDI measurements reasonably well. A major difference between simulations and experiments is that the predicted SMD profiles show a plateau around the plume centers while the measured curves do not. Simulations with SGS dispersion also predict a higher SMD compared to the other two models. This can be explained by further examining Figure 10 and Equation 6 . In a constant volume chamber where the ambient is initially stagnant, the high-speed liquid jet and fuel droplets contribute to both the resolved and SGS scales through the source terms in Equation 6. Most of the momentum exchange between the liquid phase and ambient gas happens in the near-nozzle area, as evidenced in Figure 10, where a rapidly reducing drag force magnitude within $3 \mathrm{~mm}$ away from the nozzle hole can be observed. For simulations with SGS dispersion, the relative velocity between liquid parcels and ambient gas is smaller, as compared to the other two models in the near-nozzle region. Consequently, the drag force magnitudes are smaller, and the breakup is less violent. This also explains why simulations with no dispersion and DRW model under-predict the droplet axial velocity at farther locations (i.e., $15 \mathrm{~mm}$ axial position as shown in Figure 11) since small droplets tend to accelerate faster as shown by Equation 20.

Page 9 of 15

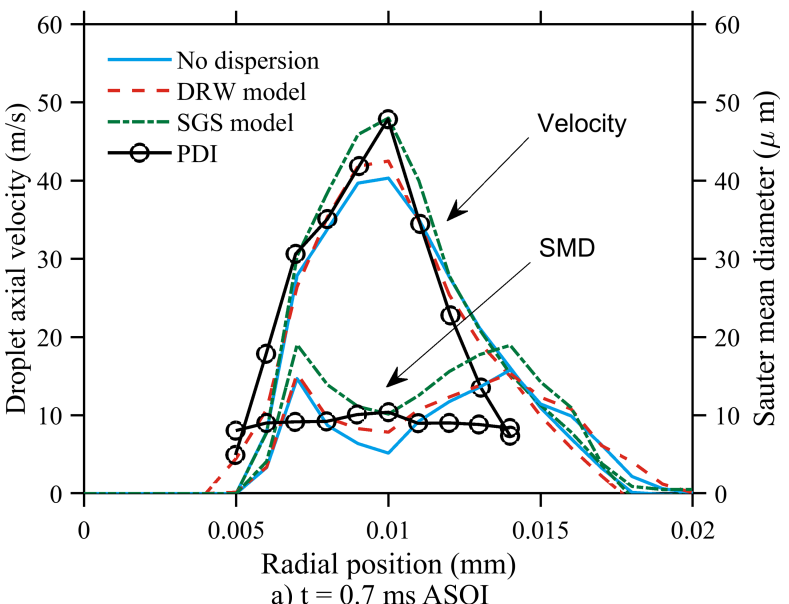

a) $\mathrm{t}=0.7 \mathrm{~ms}$ ASOI

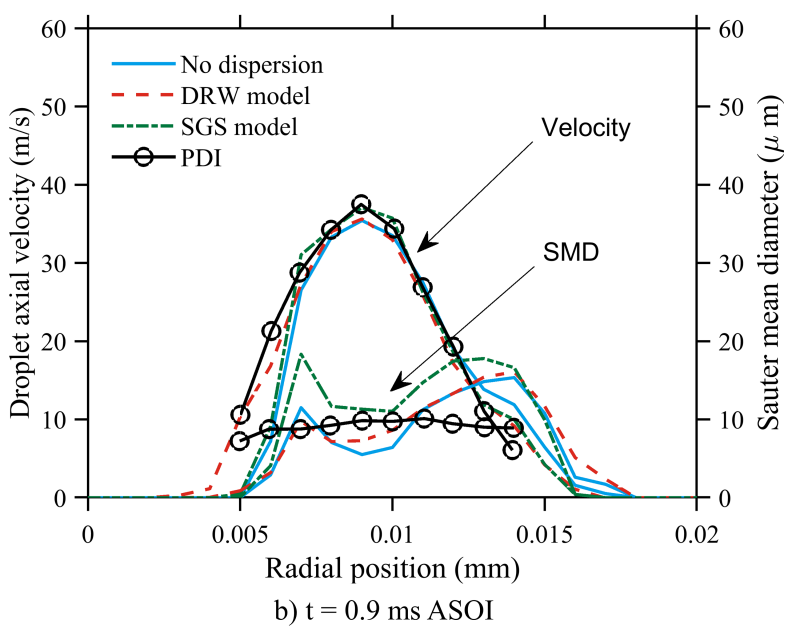

Figure 11. Radial distribution of the axial droplet velocity and SMD at $15 \mathrm{~mm}$ position under spray $\mathrm{G}$ condition. Sampling is done along the inter-plume direction as shown in Figure 3. Results at 0.7 and $0.9 \mathrm{~ms}$ ASOI are plotted in the top and bottom plots, respectively. Both simulation and measurement results are plotted with ensemble-averaged mean only. Simulation results are processed and ensemble-averaged over five realizations and eight plumes (40 samples in total).

In addition to the liquid-phase characteristics discussed in previous sections, more insight can be gained by analyzing the gas-phase velocities on the injector centerline at $\mathrm{z}=15 \mathrm{~mm}$ axial position. Results are ensemble-averaged over 5 realizations and plotted in Figure 12. All three simulations respond with a central recirculation (upward motion) due to the gas entrainment of the eight individual spray plumes. The predicted recirculating velocities continue to increase until reaching the maximum magnitudes at approximately $0.4 \mathrm{~ms}$ ASOI. No noticeable difference is observed among simulations until the recirculation starts to weaken at approximately $0.7 \mathrm{~ms}$ ASOI, which is slightly earlier than the end of injection. The axial velocity will eventually change direction and becomes positive at some time ASOI. The DRW model captures this time more accurately. After the reversal of the axial velocity, all three simulations over-predict the centerline velocity, with the largest deviation given by the SGS model. However, spray boundary conditions such as plume direction and plume cone angle have a more dramatic impact on the centerline velocity as discussed in Refs. $[20,22]$. At some time between 1.2 and $1.4 \mathrm{~ms}$ ASOI, the predicted centerline velocities start to weaken again and fall toward zero, and the predicted profiles follow each other closely. 


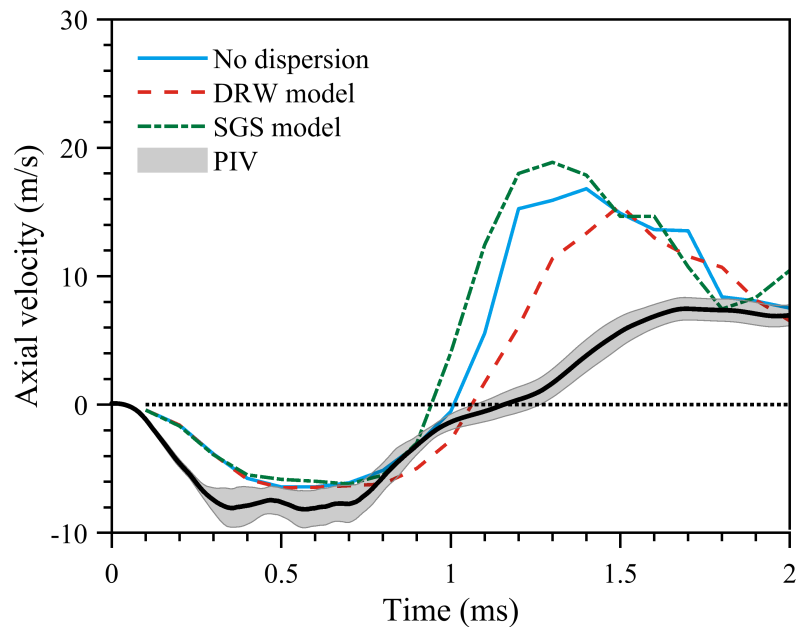

Figure 12. Temporal evolution of the axial gas-phase velocity on the injector centerline at $15 \mathrm{~mm}$ axial position. LES results are ensemble-averaged over five realizations. PIV data are plotted with the shaded area representing the standard deviation.

\section{Spray H Condition}

The evaporating, non-reacting spray $\mathrm{H}$ case is discussed for the overall assessment of the dispersion effects on the air-fuel mixing of diesel spray. The liquid and vapor penetrations predicted by LES simulations are plotted and compared with the experimental data from the ECN database in Figure 13. The initial variation of liquid phase differs between experiments and simulations. The measured liquid penetration increases progressively until the liquid length is reached at approximately $0.4 \mathrm{~ms}$ ASOI, while the predicted ones increase rapidly and reach their maximum values at a much earlier time. The LES simulation with no SGS dispersion model predicts a "spike" at approximately $0.2 \mathrm{~ms}$ ASOI. The reason for this behavior is unclear. On the other hand, the predicted liquid lengths during the quasi-steady state period of injection are virtually the same as the measured one. As for the vapor penetration, all three simulations over-predict it shortly after the start of injection. The discrepancy is noticeable until just before $1.5 \mathrm{~ms}$ ASOI. One possible reason for the difference is that vapor penetration is defined differently between simulations and experiments. The simulated vapor penetration is defined as the vertical distance between the nozzle tip and the furthest point within the vapor region, whereas the measured one is determined based on a $50 \%$ probability threshold within the inner half-angle of the spray [30]. Again, the turbulent dispersion modeling seems to have little impact on the vapor penetration. A similar finding was also reported by Tsang et al. [31] for the ECN evaporating spray A conditions.

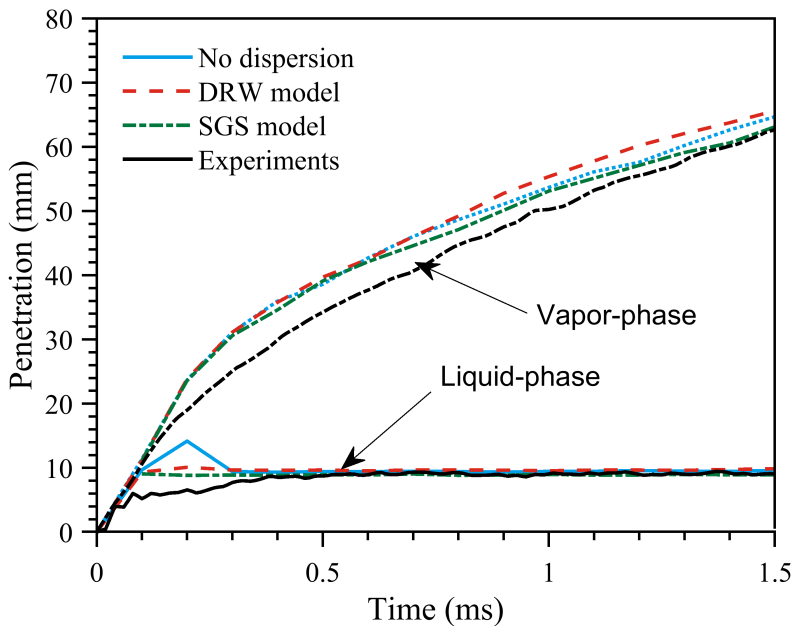

Figure 13. Axial liquid and vapor penetrations at the evaporating, non-reacting spray $\mathrm{H}$ condition of $1000 \mathrm{~K}$.

Quantitative mixing information was obtained at $0.9 \mathrm{~ms}$ ASOI when the liquid spray reaches the quasi-steady state. The simulation results and ensemble-averaged experimental data are presented in Figures 14 and 15 , where the shaded areas represent the standard deviations of the measurements. Starting with Figure 14, which shows the mixture fraction along the injector centerline, it is apparent that all three simulations predict a rapid increase in mixture fraction along the nozzle axis until reaching the maximum at a certain distance from the nozzle tip. Subsequently, all profiles exhibit a gradual drop. In the axial positions from 16 to $55 \mathrm{~mm}$, where experimental data are available, all three simulations follow the measured data closely except for some small deviations at approximately $38 \mathrm{~mm}$ below the nozzle tip.

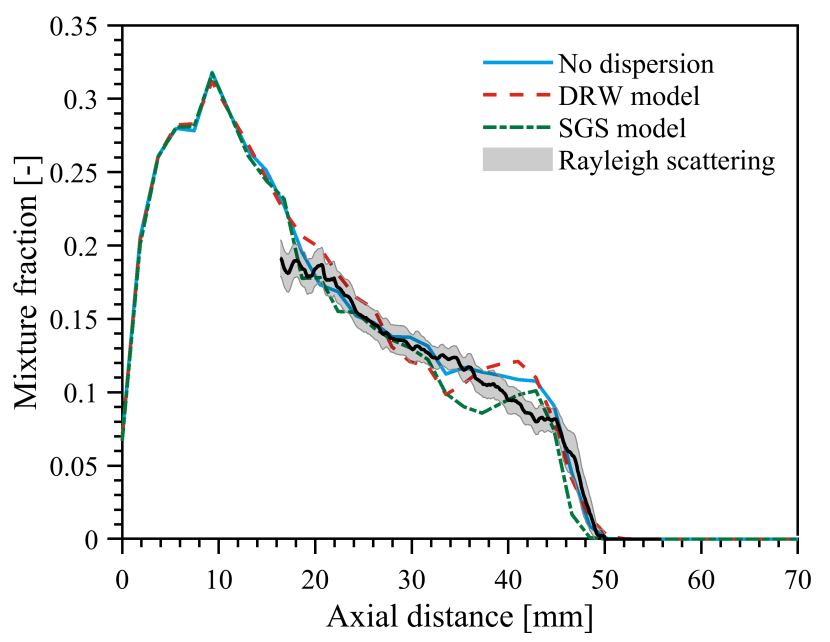

Figure 14. Fuel vapor mixture fraction on the injector centerline at $0.9 \mathrm{~ms}$ ASOI for the evaporating, non-reacting spray $\mathrm{H}$ condition of $1000 \mathrm{~K}$.

Experimental data are plotted with a shaded area representing the standard deviation.

Figure 15 shows radial profiles of fuel vapor mixture fraction at 30and 50-mm axial positions. A consistent good agreement can be seen between experiments and the LES simulation with SGS dispersion model, despite discernible discrepancies at positive radial positions. On the other hand, simulations with DRW model and no dispersion predict a narrower profile, indicating that the cross-stream dispersion of fuel droplets is under-estimated. At the $50 \mathrm{~mm}$ axial position, the measurements and simulation with SGS dispersion give nearly zero

Page 10 of 15

$01 / 14 / 2019$ 
mass fractions along the radial direction, with some hardly noticeable fluctuations. In contrast, the predicted profiles with DRW model and no dispersion modeling still show a considerable amount of fuel vapor mixture fraction.

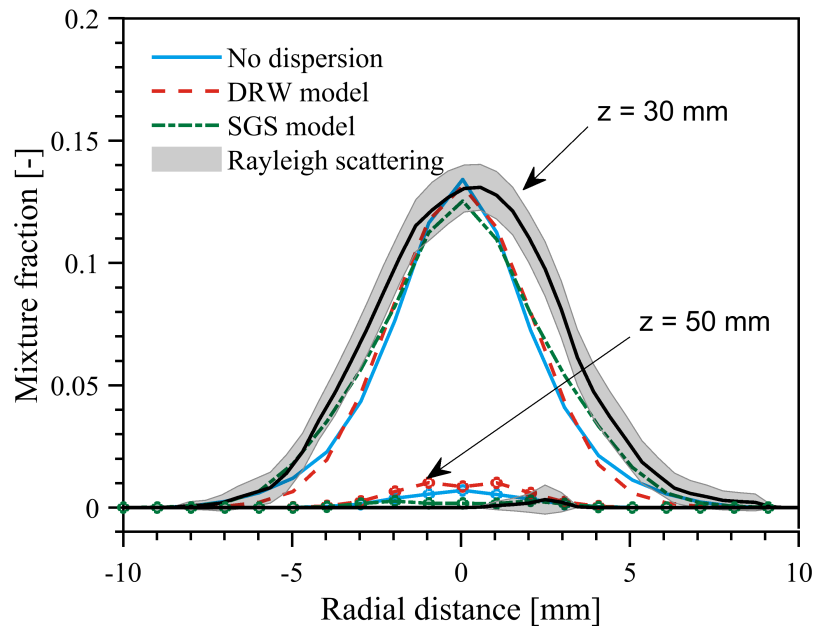

Figure 15. Radial distribution of the fuel vapor mixture fraction at 30- and 50$\mathrm{mm}$ axial positions for the evaporating, non-reacting spray $\mathrm{H}$ condition of $1000 \mathrm{~K}$. Experimental data are plotted with a shaded area representing the standard deviation.

Figure 16 shows the magnitudes of the droplet drag force along the nozzle centerline for all three simulation cases. Mass-averaged modeling results are sampled and ensemble-averaged at $0.8,0.9$, and $1.0 \mathrm{~ms}$ ASOI. A similarity can be found between Figure 10 and 16 . However, the maximum magnitude in Figure 16 is about 12 times larger than that in Figure 10. This is expected since the average injection velocity of spray $\mathrm{H}$ is around $600 \mathrm{~m} / \mathrm{s}$, which is about 3.5 times larger than that in spray $\mathrm{G}$.

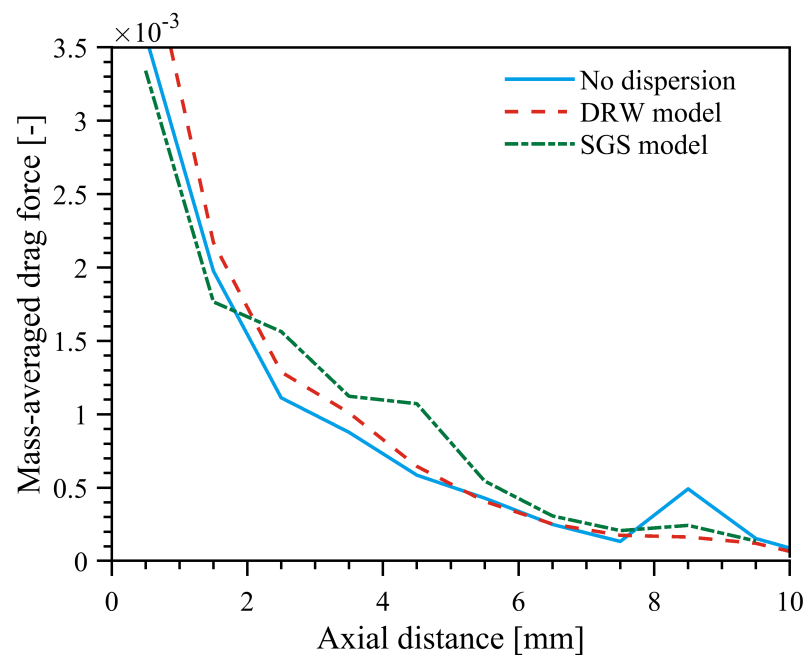

Figure 16. Mass-averaged aerodynamic drag force sampled along the injector centerline direction. Results are ensemble-averaged at $0.8,0.9$, and $1.0 \mathrm{~ms}$ ASOI.

Next, the reacting spray $\mathrm{H}$ was studied based on the calibrated nonreacting spray $\mathrm{H}$ case. The simulations were performed using a reduced chemical kinetic model developed by Ra and Reitz [32]. Besides, the SpeedCHEM fast chemistry solver developed by Perini et al. [33] was coupled with OpenFOAM for faster solutions. Table 4 presents the measured and predicted ignition delays at the ambient temperature of $1000 \mathrm{~K}$ and at the oxygen level of $21 \%$ by volume.

Page 11 of 15
The measured ignition delay is determined based on the pressure rise corresponding to the high-temperature combustion. In the simulations, the ignition delay is defined as the first time at which the Favre-averaged $\mathrm{OH}$ mass fraction reaches $2 \%$ of the maximum in the domain after a stable flame is established [26]. As Table 4 shows, all three simulations predict a retarded timing of ignition, which could be due to the different definitions of ignition delay between simulations and experiments. Another possible reason for the discrepancy is the chemical mechanism being used. Though this reduced primary reference fuel (PRF) mechanism improves the computational efficiency over detailed mechanisms, the ignition characteristics may not be captured very well under certain conditions.

Table 4. Ignition delay and flame lift-off length for reacting spray $\mathrm{H}$ at the oxygen level of $21 \%$ (by volume) and ambient temperature of $1000 \mathrm{~K}$.

\begin{tabular}{|l|l|l|}
\hline & Ignition delay (ms) & Lift-off length $(\mathbf{m m})$ \\
\hline Experiments & 0.53 & 17.0 \\
\hline No dispersion & 0.58 & 27.1 \\
\hline DRW model & 0.57 & 27.0 \\
\hline SGS model & 0.57 & 27.9 \\
\hline
\end{tabular}

Figure 17 shows the flame lift-off length profiles for all three simulations. The mean value of measured lift-off length from $\mathrm{OH}$ chemiluminescence is also plotted. It can be seen that all simulations over-predict the flame lift-off length by about $10 \mathrm{~mm}$ after the ignition starts. Possible reasons for this rather large difference could be the reduced PRF mechanism and the different methods to define the flame lift-off length between experiments and simulations. The chemiluminescence diagnostic is a line-of-sight technique and therefore a line-of-sight integrated $\mathrm{OH}$ radical is more reasonable than the current ECN modeling standard, which is $2 \%$ of the local maximum Favre-averaged $\mathrm{OH}$ mass fraction [26]. However, this conceptual difference should not make a major difference in the results as the $\mathrm{OH}$ mass fractions rise rapidly. The SGS dispersion model does help smooth the flame lift-off length, even though the mean lift-off length is slightly higher than that given by the other two models, as Table 4 shows.

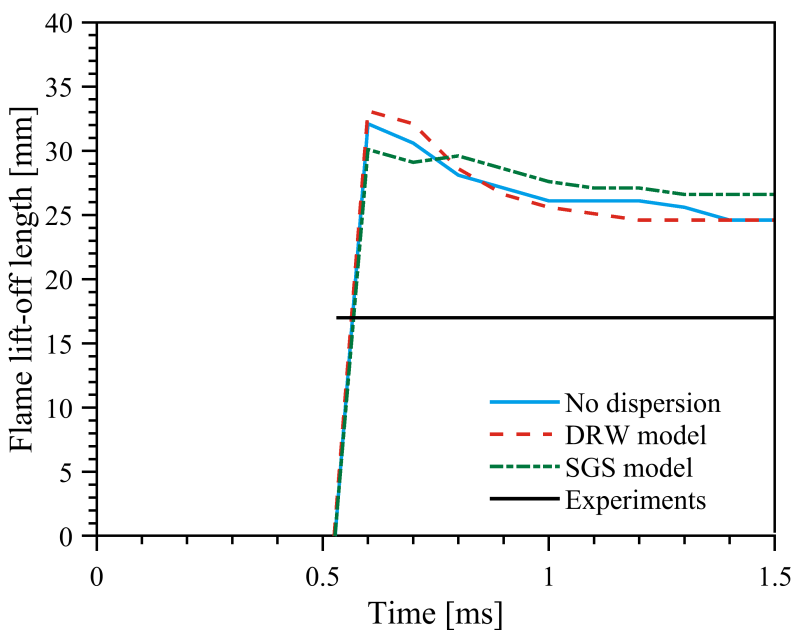

Figure 17. Flame lift-off length for reacting spray $\mathrm{H}$ at the oxygen level of $21 \%$ (by volume) and the ambient temperature of $1000 \mathrm{~K}$. Experimental data are plotted with the mean value only. 
Propagating flame structures are analyzed by plotting the contour plots of fuel mixture fraction, Favre-averaged temperature, and $\mathrm{OH}$ radicals at 0.5 and $1.5 \mathrm{~ms}$ ASOI, as shown in Figures 18 and 19. At $0.5 \mathrm{~ms}$ ASOI, a rise of the temperature can be seen downstream of the spray, indicating the premixed burn before high-temperature combustion. The DRW model and present SGS model also predict slightly higher temperatures of the fuel-vapor mixture, which can contribute to the advanced ignition delay. Little to no $\mathrm{OH}$ radicals were produced at that time instant since ignition had yet to take place.
At $1.5 \mathrm{~ms}$ ASOI, the high-temperature combustion has already taken place and the flame structure has reached a quasi-steady state. The diffusion flames characterized by high temperature and high $\mathrm{OH}$ radicals can be clearly seen in Figure 19. Note that the simulated vapor penetration with SGS model is slightly shorter than that by the other two models. The characteristic size of the high temperature and high $\mathrm{OH}$ region is reduced by the current SGS model as well.
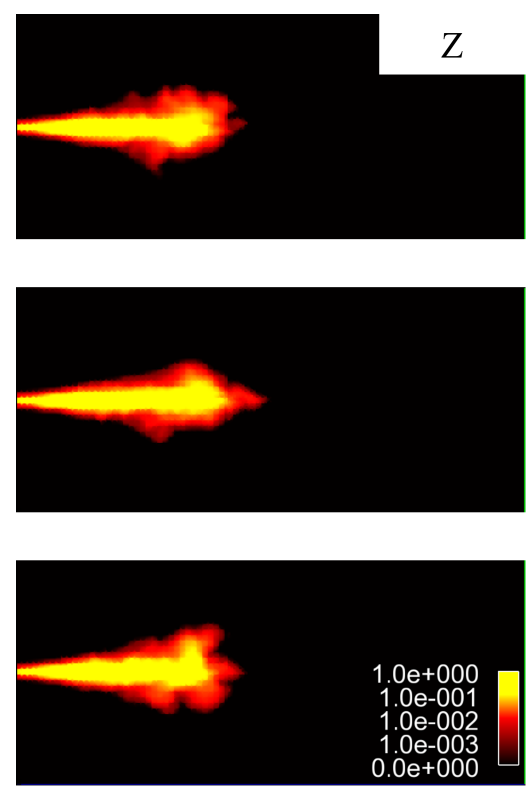

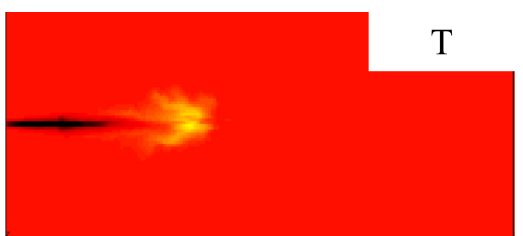

a) no dispersion

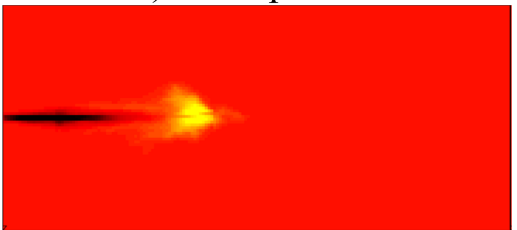

b) DRW model

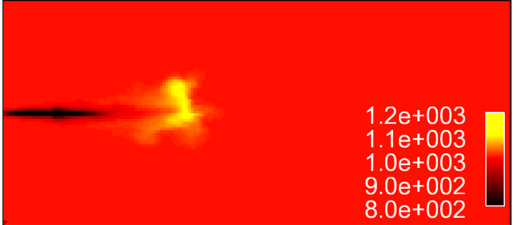

c) SGS model
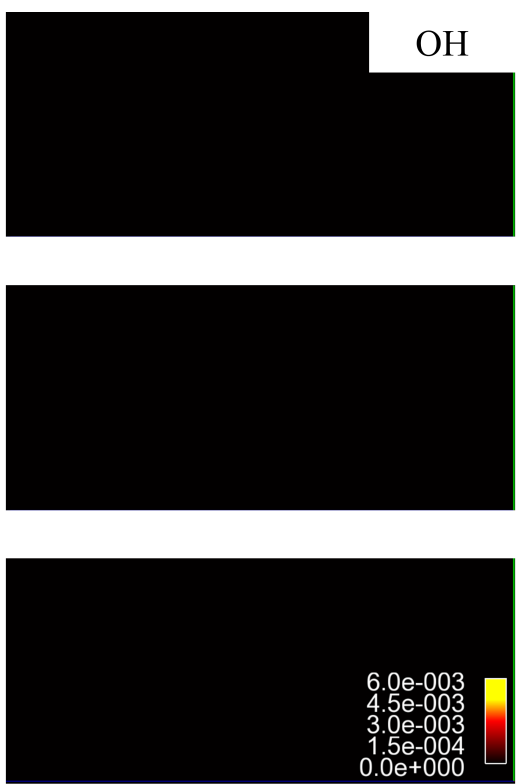

Figure 18. Contour plots of fuel mixture fraction Z, Favre-averaged temperature T, and OH radical under reacting spray H condition at $0.5 \mathrm{~ms}$ ASOI. Figures on the top, middle, and bottom rows show results from simulations with no dispersion, DRW model, and present SGS model, respectively.
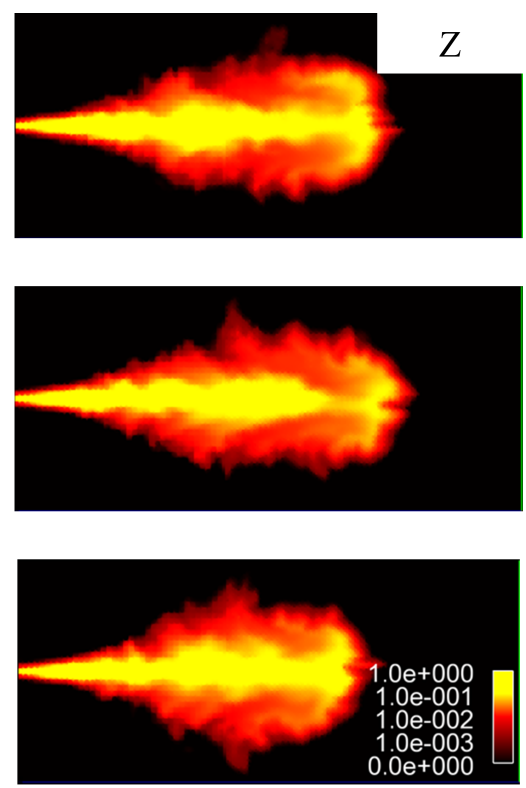

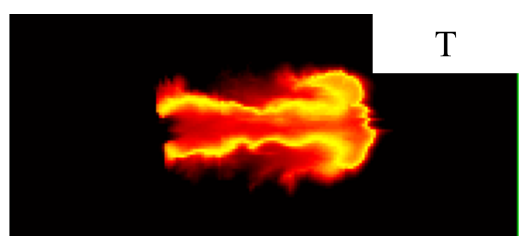

a) no dispersion

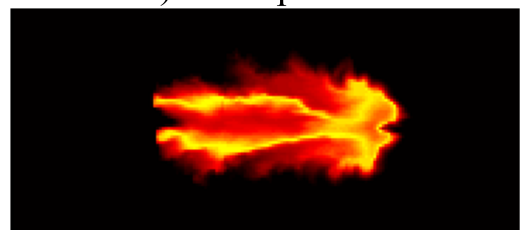

b) DRW model

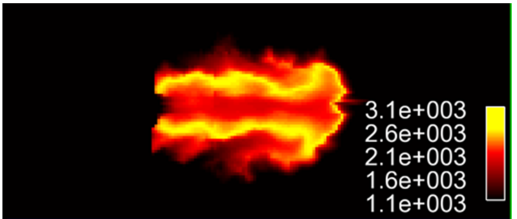

c) SGS model
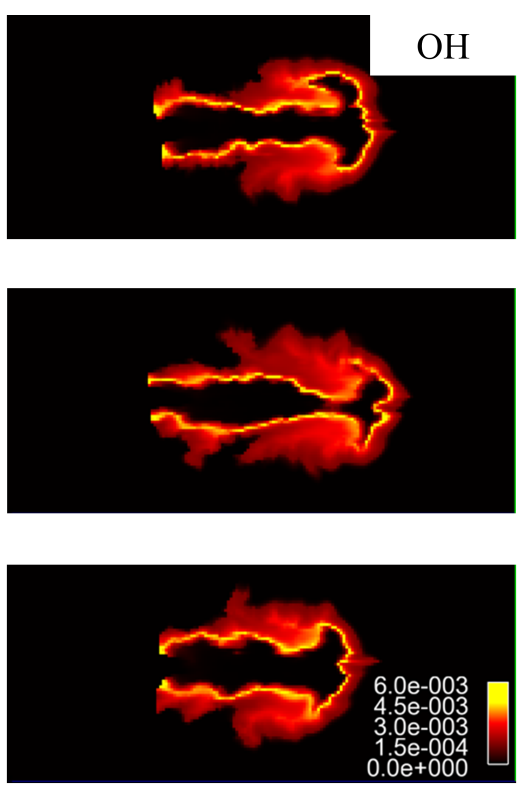

Figure 19. Contour plots of fuel mixture fraction Z, Favre-averaged temperature T, and OH radical under reacting spray H condition at 1.5 ms ASOI. Figures on the top, middle, and bottom rows show results from simulations with no dispersion, DRW model, and present SGS model, respectively. 


\section{Summary and Conclusions}

In this paper, an SGS model for the turbulent dispersion was proposed in the context of large-eddy simulation. The model relies on the ADM method to obtain the large-scale motion of the order of LES filter width or larger. The SGS fluid field is modeled using a modified Langevin model based on the approach proposed by Pozorski and Apte [4]. ECN spray experiments at the standard spray $\mathrm{G}$ and high-temperature spray $\mathrm{H}$ conditions were used to validate the model. Simulations with the RANS-type DRW model and no dispersion model were also performed for comparison purposes. The major findings from this work are summarized in the following:

1. For both spray $\mathrm{G}$ and spray $\mathrm{H}$ conditions, the turbulent dispersion does not have a significant impact on the liquidand vapor-phase penetration, though slight improvements can be found in simulations with the current SGS model.

2. For high-speed sprays in constant volume chambers, the majority of the momentum exchange between the liquid phase and ambient gas occurs in the near-nozzle region (less than $3 \mathrm{~mm}$ away from the nozzle hole for spray conditions studied in this paper).

3. In the near-nozzle region, the aerodynamic drag magnitudes predicted by the current SGS dispersion model are slightly lower than that with the other two models. For spray $\mathrm{G}$, this results in a slower breakup speed and, hence, a higher droplet axial velocity and SMD.

4. In the downstream of the nozzle exit, the predicted massaveraged droplet drag magnitudes are higher with the current SGS model, due to the larger droplet sizes.

5. Radial dispersion of the liquid droplets has a considerable impact on both the liquid and vapor phase concentrations. For spray G, simulations with the current SGS dispersion model show an improved projected liquid volume fraction along the injector centerline. For spray $\mathrm{H}$, the predicted radial profiles of fuel vapor mixture fraction are also improved by the current SGS model, though the difference is minor.

6. For the reacting spray $\mathrm{H}$ condition, the current SGS dispersion model does help smooth the flame lift-off length.

\section{References}

1. Gosman, A.D. and loannides, E., "Aspects of Computer Simulation of Liquid-Fueled Combustors," J. Energy 7(6):482-490, 1983, doi:10.2514/3.62687.

2. Kuerten, J.G.M., "Subgrid modeling in particle-laden channel flow," Phys. Fluids 18(2), 2006, doi:10.1063/1.2176589.

3. Shotorban, B. and Mashayek, F., "Modeling subgrid-scale effects on particles by approximate deconvolution," Phys. Fluids 17(8):1-4, 2005, doi:10.1063/1.2001691.

4. Pozorski, J. and Apte, S. V., "Filtered particle tracking in isotropic turbulence and stochastic modeling of subgridscale dispersion," Int. J. Multiph. Flow 35(2):118-128, 2009, doi:10.1016/j.ijmultiphaseflow.2008.10.005.

5. Amsden, A.A., O'Rourke, P.J., and Butler, T.D., "KIVA-II: A Computer Program for Chemically Reactive Flows with Sprays," Los Alamos Natl. Lab., LA-11560-MS, 1989, doi:10.1007/BF01054829.

6. Bharadwaj, N., "Large Eddy Simulation Turbulence Modeling of Spray Flows," University of Wisconsin Madison, 2010.
7. Rutland, C.J., "Large-eddy simulations for internal combustion engines - A review," Int. J. Engine Res. 12(5):421-451, 2011, doi:10.1177/1468087411407248.

8. Celik, I., Yavuz, I., and Smirnov, A., "Large eddy simulations of in-cylinder turbulence for internal combustion engines: A review,” ISBN 1468087011545, 2001, doi:10.1243/1468087011545389.

9. Tsang, C.W., Trujillo, M.F., and Rutland, C.J., "Large-eddy simulation of shear flows and high-speed vaporizing liquid fuel sprays," Comput. Fluids 105:262-279, 2014, doi:10.1016/j.compfluid.2014.09.014.

10. Pomraning, E. and Rutland, C.J., "Dynamic One-Equation Nonviscosity Large-Eddy Simulation Model," AIAA J. 40(4), 2002.

11. Bharadwaj, N., Rutland, C.J., and Chang, S., "Large eddy simulation modelling of spray-induced turbulence effects," Int. J. Engine Res. 10(2):97-119, 2009,

doi:10.1243/14680874JER02309.

12. Ghosal, S., Lund, T.S., Moin, P., and Akselvoll, K., "A dynamic localization model for large-eddy simulation of turbulent flows," J. Fluid Mech. 286:229-255, 1995, doi:10.1017/S0022112095000711.

13. MacInnes, J.M. and Bracco, F. V., "Stochastic particle dispersion modeling and the tracer-particle limit," Phys. Fluids A 4(12):2809-2824, 1992, doi:10.1063/1.858337.

14. Stolz, S., Adams, N.A., and Kleiser, L., “An approximate deconvolution model for large-eddy simulation with application to incompressible wall-bounded flows," Phys. Fluids 13(4):997-1015, 2001, doi:10.1063/1.1350896.

15. Crowe, C.T., Chung, J.N., and Troutt, T.R., "Particle mixing in free shear flows,” Prog. Energy Combust. Sci. 14(3):171194, 1988, doi:10.1016/0360-1285(88)90008-1.

16. ECN, "Engine Combustion Network(ECN): Gasoline Data Search," https://ecn.sandia.gov/gasoline-data-search/, 2018.

17. Reitz, R.D. and Beale, J.C., "Modeling Spray Atomization With the Kelvin-Helmholtz/Rayleigh-Taylor Hybrid Model," At. Sprays 9(6):623-650, 1999, doi:10.1615/AtomizSpr.v9.i6.40.

18. Dam, N. Van and Rutland, C., "Adapting diesel large-eddy simulation spray models for direct-injection spark-ignition applications," Int. J. Engine Res. 17(3):291-315, 2016, doi:10.1177/1468087415572034.

19. Li, H. and Rutland, C., "Uncertainty Quantification of Direct Injection Diesel and Gasoline Spray Simulations," SAE International, 2017, doi:10.4271/2017-01-0836.Copyright.

20. Sphicas, P., Pickett, L.M., Skeen, S., Frank, J., Lucchini, T., Sinoir, D., D’Errico, G., Saha, K., and Som, S., “A Comparison of Experimental and Modeled Velocity in Gasoline Direct-Injection Sprays with Plume Interaction and Collapse," SAE Int. J. Fuels Lubr. 10(1):2017-01-0837, 2017, doi:10.4271/2017-01-0837.

21. Manin, J., Skeen, S.A., Pickett, L.M., Parrish, S.E., and Markle, L.E., "Experimental Characterization of DI Gasoline Injection Processes," 2015.

22. Pickett, L.M., "Spray G Langrangian Modeling," ECN 5 proceedings, Detroit, MI, MI, 2016.

23. ECN, "Engine Combustion Network(ECN): Diesel Spray Data Search," https://ecn.sandia.gov/diesel-spraycombustion/experimental-data-search/.

24. Lucchini;, T., Paredi;, D., and Lacey, J., "Topic 10: Evaporative Spray G (external, plume interaction, flash boiling)," ECN 6 proceedings, Valencia, 2018.

25. Parrish, S., "Gasoline Spray (Spray G) Topic 3.4 Drop Size Measurement," Engine Combustion Network 3rd Workshop, Engine Combustion Network, Detroit, 2014.

Page 13 of 15 
26. ECN, "Modeling Standards and Recommendations."

27. Lavision, "Techniques Mie/Rayleigh/Raman,"

https:/www.lavision.de/en/techniques/mie-rayleigh-raman/, 2018.

28. ECN, "Engine Combustion Network(ECN): Liquid

Penetration Length," https://ecn.sandia.gov/gasoline-spraycombustion/experimental-diagnostics/liquid-penetrationlength/, 2018.

29. Dam, N.E. Van, "Large-eddy Simulations of Direct-injection Spark-ignition Engine Spray and Flow Variability," 2015.

30. Naber, J. and Siebers, D.L., "Effects of Gas Density and Vaporization on Penetration and Dispersion of Diesel Sprays," (412), 1996, doi:10.4271/960034.

31. Tsang, C. and Rutland, C.J., "Effects of Sub-Grid Scale ( SGS ) Dispersion Modeling on Large-Eddy Simulation ( LES ) of Non-Evaporative and Evaporative Diesel Sprays," ILASS Am. 29th Annu. Conf. Liq. At. Spray Syst. Atlanta, GA, May 2017 (May), 2017.

32. Ra, Y. and Reitz, R.D., "A reduced chemical kinetic model for IC engine combustion simulations with primary reference fuels," Combust. Flame 155(4):713-738, 2008, doi:10.1016/j.combustflame.2008.05.002.

33. Perini, F., Galligani, E., Cantore, G., and Reitz, R.D., "Validation of a Sparse Analytical Jacobian Chemistry Solver for Heavy-Duty Diesel Engine Simulations with Comprehensive Reaction Mechanisms," SAE Tech. Pap. 2012-01-1974, 2012, doi:10.4271/2012-01-1974.

\section{Contact Information}

\section{Hongjiang Li}

Engine Research Center

University of Wisconsin-Madison

1011 Engineering Research Building

1500 Engineering Drive

Madison, WI 53706-1609

hongjiang.li@wisc.edu

\section{Acknowledgments}

This work is supported by the FUELCOM collaborative project between King Abdullah University of Science and Technology and Saudi Aramco Oil Co. The computing resources at UW-Madison High Throughput Computing were used to obtain results presented in this publication.

\section{Definitions/Abbreviations}

$\begin{array}{ll}\text { ADM } & \text { Approximate Deconvolution Method } \\ \text { ASOI } & \text { After Start of Injection } \\ \text { CFD } & \text { Computational Fluid Dynamics } \\ \text { DBI } & \text { Diffused Backlit Imaging } \\ \text { DDF } & \text { Droplet Distribution Function } \\ \text { DISI } & \text { Direction Injection Spark Ignition } \\ \text { DRW } & \text { Discrete Random Walk } \\ \text { ECN } & \text { Engine Combustion Network } \\ \text { EOI } & \text { End of Injection } \\ \text { ERC } & \text { Engine Research Center } \\ \text { IC } & \text { Internal Combustion }\end{array}$

Page 14 of 15

$01 / 14 / 2019$

KH-RT

LE

LES

PDI

PLV

PRF

RANS

SDE

SGS

SNL
Kelvin-Helmholtz Rayleigh-Taylor

Lagrangian Eulerian

Large-eddy Simulation

Phase Doppler Interferometry

Projected Liquid Volume

Primary Reference Fuel

Reynolds-averaged Navier-Stokes

Stochastic Differential Equation

Sub-grid Scale

Sandia National Laboratory 


\section{Appendix}

Features of the Integrated Atomization/Breakup Model

- Modern DISI injectors share the similar multi-hole design to its diesel counterpart. However, gasoline injectors operate at much lower system pressure. Gasoline also has a lower density and a lower viscosity compared to diesel. As a result, the leading breakup mechanisms between direct injection diesel and gasoline sprays are very different.

- $\quad$ The IAB model was proposed by incorporating the bag/bag-stamen breakup regimes, which were found to be important for the breakup simulation in direct injection gasoline sprays.

- The IAB model builds on the LE approach and treats the atomization and breakup as indistinguishable processes. The justification is that internal phase-change (e.g., cavitation, flash boiling) and internal turbulence are prone to exist in DISI injectors, which lead to little to no intact liquid-core in the near-nozzle area.

- Two sub-models, representing different breakup regimes, are used to describe the atomization/breakup processes for liquid parcels. The choice of sub-model depends on the droplet Weber number, which was found experimentally to be the only determining factor for transitions among various breakup regimes in direct injection gasoline sprays.

- The model was found to give realistic and accurate predictions for spray characteristics such as droplet velocity, SMD, and penetrations.

- The model was also found to perform reasonably well across various ambient temperature and density conditions under DISI engine-like conditions without the need to tune the model parameters. 